\title{
The ptsG Gene Encoding the Major Glucose Transporter of Bacillus cereus C1L Participates in Root Colonization and Beneficial Metabolite Production to Induce Plant Systemic Disease Resistance
}

\author{
Chia-Hua Lin, ${ }^{1}$ Chia-Yen Lu, ${ }^{1}$ Ann-Tze Tseng, ${ }^{1}$ Chien-Jui Huang, ${ }^{1,2}$ Yu-Ju Lin, ${ }^{1}$ and Chao-Ying Chen ${ }^{1,+}$ \\ ${ }^{1}$ Department of Plant Pathology and Microbiology, National Taiwan University, Taipei 10617, Taiwan \\ ${ }^{2}$ Department of Plant Medicine, National Chiayi University, Chiayi 60004, Taiwan
}

Accepted 12 September 2019.

\begin{abstract}
Rhizosphere interactions between microorganisms and plants have great influence on plant health. Bacillus cereus $\mathrm{C1L}$, an induced systemic resistance (ISR)-eliciting rhizobacterium from Lilium formosanum, can protect monocot and dicot plants from disease challenges. To identify the ISR-involved bacterial genes, the systemic protection effect of transposon-tagged mutants of $B$. cereus C1L against southern corn leaf blight (SCLB) was surveyed, and a mutant of the $p t s G$ gene encoding glucose-specific permease of the phosphotransferase system was severely impaired in the abilities of disease suppression and root colonization. The pts $G$ mutant lost the preferential utilization of glucose and showed reduction of glucose-assisted growth in minimal medium. A promoter-based reporter assay revealed that $p t s G$ expression could be activated by certain sugar constituents of maize root exudates, among which B. cereus $\mathrm{C} 1 \mathrm{~L}$ exhibited the highest chemotactic response toward glucose, whereas neither of them could attract the ptsG mutant. Additionally, $p t s G$ deficiency almost completely abolished glucose uptake of $B$. cereus C1L. Metabolite analysis indicated that the lack of $p t s G$ undermined glucose-induced accumulation of acetoin and 2,3-butanediol in $B$. cereus $\mathrm{C} 1 \mathrm{~L}$, both eliciting maize ISR against SCLB. Pretreatments with B. cereus $\mathrm{C} 1 \mathrm{~L}$, ptsG mutant, acetoin, and 2,3-butanediol enhanced defense-related reactive oxygen species accumulation and callose deposition at different levels that were positively correlated to their ISR-eliciting activities. Thus, glucose uptake-mediating pts $G$ participates in ISR elicitation by endowing $B$. cereus $\mathrm{C} 1 \mathrm{~L}$ with the full capacities for root colonization and beneficial glucose metabolite production, providing a clue regarding how ISR-mediating rhizobacteria create a mutually beneficial relationship with various plant species.
\end{abstract}

Chia-Hua Lin and Chia-Yen Lu contributed equally.

${ }^{\dagger}$ Corresponding author: C.-Y. Chen; cychen@ntu.edu.tw

Funding: This study was financially supported by the Ministry of Science and Technology, and the Council of Agriculture, Taiwan, Republic of China.

*The $\boldsymbol{e}$-Xtra logo stands for "electronic extra" and indicates that supplementary materials are published online.

The author(s) declare no conflict of interest.

๑) 2020 The American Phytopathological Society
Keywords: Bacillus cereus, biocontrol, glucose metabolites, glucose uptake and chemotaxis, induced systemic resistance, $p t s G$

Rhizosphere microorganisms have various influences on plants. Rhizobacteria can enhance plant growth, protect plants from disease challenges, or both through diverse mechanisms and are considered to have high potential in agricultural applications (Gouda et al. 2018; Mhlongo et al. 2018). Induced systemic resistance (ISR) of plants is a type of systemically enhanced resistance against a broad spectrum of pathogens, usually elicited by particular rhizobacteria via the action of certain bacterial cell components, other ISR-eliciting molecules, or both (Burketova et al. 2015; Chung et al. 2016; Fincheira and Quiroz 2018; Kanchiswamy et al. 2015; Sharifi and Ryu 2018). Characterizing the disease suppression mechanisms and bacterial genes involved in ISR elicitation greatly facilitates the development of plant disease control strategies.

Plants interact with rhizobacteria through their roots, which secrete a mixture of compounds as root exudates, comprising sugars, organic acids, proteins, amino acids, fatty acids, and secondary metabolites (Badri and Vivanco 2009; Gunina and Kuzyakov 2015; Hütsch et al. 2002; Whipps 1990). Certain constituents of root exudates have been known to attract the surrounding microbes to achieve symbiotic relationships beneficial for plants (Rudrappa et al. 2008). Changes in root exudate constituents significantly influence the rhizosphere microbiome composition and rhizobacterial gene expression, especially genes involved in nutrition utilization, chemotaxis, motility, and metabolite biosynthesis (Fan et al. 2012; Lu et al. 2017; Meziane et al. 2005). Accordingly, some root-exudate constituents play critical roles in the establishment of rhizobacterium-mediated ISR of plants via altering microbial behaviors such as nutrition uptake, root colonization, and beneficial metabolite production.

Bacillus cereus $\mathrm{C} 1 \mathrm{~L}$, a gram-positive ISR-mediating strain and a plant growth-promoting rhizobacterium (PGPR) from Lilium formosanum in Taiwan, can promote plant growth and systemically protect monocot and dicot plants from disease challenges such as lily gray mold, caused by Botrytis elliptica (Berk.) Cooke, tobacco gray mold, caused by Botrytis cinerea Pers., and southern corn leaf blight (SCLB), caused by Cochliobolus heterostrophus Drechsler (Huang et al. 2010, 2012a and b, 2017; Lai et al. 2016). The outstanding trait of this versatile strain highlights its application potential in agriculture. In this study, a Bacillus cereus $\mathrm{C} 1 \mathrm{~L}$ mutant strain with transposon-tagging in the pts $G$ gene presumably encoding a glucose-specific component of the phosphotransferase system 
(PTS) was found to show reduction in ISR-eliciting activity against SCLB. Because glucose in soil is mostly released from plant roots and is likely a host signal for rhizosphere microorganisms (Badri and Vivanco 2009; Gunina and Kuzyakov 2015; Hütsch et al. 2002; Whipps 1990), bacterial pts $G$ participating in the ISR elicitation-related interaction between plant and B. cereus $\mathrm{C} 1 \mathrm{~L}$ is presumed.

PTS mediates the major carbohydrate uptake of bacteria via transferring the phosphoenolpyruvate-originated phosphoryl group onto the targeted carbohydrate to mediate the active transport of carbohydrate across the membrane, and has broad influences on physiological processes such as carbon metabolism and secondary metabolite production (Cabrera-Valladares et al. 2012; Deutscher et al. 2006; Kanchiswamy et al. 2015; Kotrba et al. 2001). Typically, PTS comprises two general proteins, phosphoenolpyruvate-protein phosphotransferase enzyme I (EI) and histidine-containing phosphocarrier protein (HPr), as well as one substrate-specific permease enzyme II (EII). The EII permease consists of at least three structurally distinct domains of IIA, IIB, and IIC in the form of a multidomain polypeptide or several single-domain subunits, and the substrate specificity of EII is determined by the IIA domain. The glucose-specific PTS is encoded by the $p t s G H I$ operon that contains $p t s G, p t s H$, and $p t s I$ genes encoding glucose-specific EII permease (EII ${ }^{\mathrm{Glc}}$ ), HPr and EI, respectively (Clore and Venditti 2013). EII ${ }^{\mathrm{Glc}}$ has been known to be involved in the transport and phosphorylation of glucose and in the production of secondary carbohydrate metabolites (Cabrera-Valladares et al. 2012; Deutscher et al. 2006; Kanchiswamy et al. 2015; Kotrba et al. 2001).

Glucose can serve as an enhancer for pts operon expression and as a chemoattractant for bacteria (De Reuse and Danchin 1991; De Reuse et al. 1992), and certain bacterial carbohydrate metabolites can promote growth and elicit ISR in many plant species (Chung et al. 2016; Fincheira and Quiroz 2018; Kanchiswamy et al. 2015; Sharifi and Ryu 2018). The glucose uptake-mediating pts $G$ is, accordingly, supposed to participate in ISR elicitation by $B$. cereus $\mathrm{C} 1 \mathrm{~L}$, probably via altering root colonization and beneficial metabolite production. In this study, the involvement of the $p t s G$ gene in the biocontrol-related crosstalk between $B$. cereus $\mathrm{C} 1 \mathrm{~L}$ and host plant was investigated using the transposon-tagged $p t s G$ mutant strain and maize-SCLB system. For the first time, the functions of the rhizobacterial ptsG gene in host plant targeting, nutrition uptake, and beneficial metabolite production critical for ISR elicitation was expounded. Consequently, these findings provide evidence for the glucose-related give-and-take interaction, which is presumed to be widely adopted in plantrhizosphere microbe mutualism, and would facilitate plant health management with beneficial rhizobacteria for sustainable agriculture.

\section{RESULTS}

\section{The pts $G$ mutant of $B$. cereus $\mathrm{C} 1 \mathrm{~L}$ is reduced in disease} suppression and root colonization abilities.

To identify the key bacterial gene for $B$. cereus $\mathrm{C} 1 \mathrm{~L}$-elicited ISR, the systemic protection efficiency of 340 mutants randomly selected from a Tn917acl transposon-tagged library of B. cereus $\mathrm{C} 1 \mathrm{~L}$ was surveyed using the maize-SCLB system (Supplementary Fig. S1). Mutant M71, which showed the most decrease in biocontrol activity, was selected for the further study. Mutant M71 had one Tn917ac1 transposon inserted into the $p t s G$ gene indicated by the transposon-flanking sequence and Southern blot analyses (Supplementary Fig. S2). In the B. cereus C1L genome (GenBank accession CP022445, Huang et al. 2017), ptsG is a single-copy gene presumably encoding glucose-specific PTS permease (EII ${ }^{\mathrm{Glc}}$ ), which contains the EIIC, EIIB, and EIIA domains in a single polypeptide chain (Supplementary Fig. S3), and located in the ptsGHI operon that includes two other downstream genes, $p t s H$ and $p t s I$, encoding $\mathrm{HPr}$ and EI, respectively (Fig. 1A). Reverse transcriptionpolymerase chain reaction (RT-PCR) for ptsGHI operon expression revealed that mutant M71 only failed to transcribe pts $G$ compared with the wild-type $B$. cereus $\mathrm{C} 1 \mathrm{~L}$ (Fig. 1A). The contribution of ptsG to ISR triggered by $B$. cereus $\mathrm{C} 1 \mathrm{~L}$ was examined by comparing the symptom and disease severity of maize seedlings, which were challenged by $C$. heterostrophus $\mathrm{CH} 1$ at one day after root drench with bacterial suspensions. In contrast to $B$. cereus $\mathrm{C} 1 \mathrm{~L}$, which conferred a great protection effect, mutant M71 did not result in significant suppression of SCLB (Fig. 1B).

Root colonization by beneficial bacterial strains is an essential step for ISR establishment. To investigate the involvement of ptsG in the root colonization of B. cereus $\mathrm{C} 1 \mathrm{~L}$, the surface and endophytic colonization levels of $B$. cereus $\mathrm{C} 1 \mathrm{~L}$ and mutant M71 in the roots of maize seedlings were compared. The populations of $B$. cereus $\mathrm{C} 1 \mathrm{~L}$ and mutant $\mathrm{M} 71$ on root surface at 4 days after drenching with a bacterial suspension of

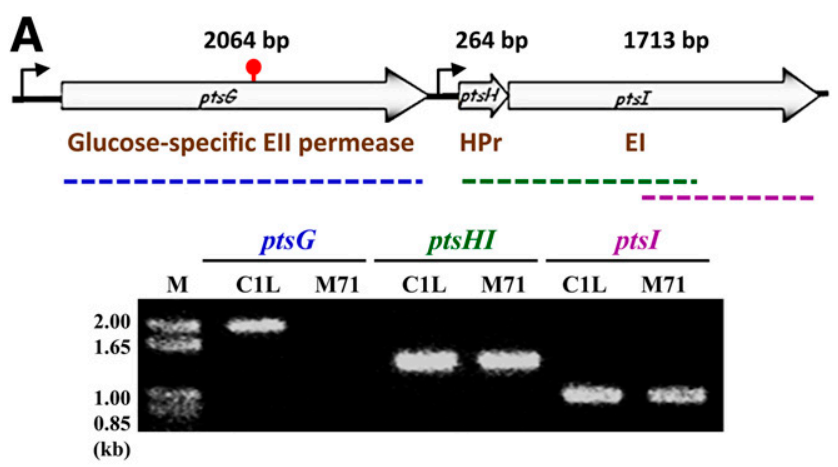

B
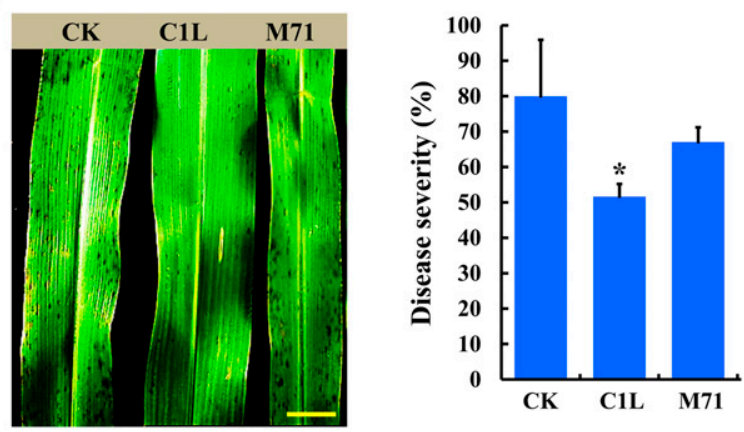

Fig. 1. Mutant M71 of Bacillus cereus $\mathrm{C} 1 \mathrm{~L}$ fails to express the pts $G$ gene and reduces disease suppression ability. A, The insertion of transposon Tn917acl in the ptsG gene of the ptsGHI operon in the mutant M71 genome is marked by a red sign. Bent arrows indicate the positions and direction of predicted promoters. The ptsGHI operon expression in B. cereus $\mathrm{C} 1 \mathrm{~L}$ and mutant M71 was detected by specifically amplifying $p t s G-$ ptsHI-, or ptsI-bearing transcripts corresponding to the regions indicated by blue, green, and purple dotted lines, respectively. $\mathrm{M}=1 \mathrm{~kb}$ Plus DNA Ladder (Invitrogen Corp.). B, Systemic suppression of Southern corn leaf blight by B. cereus $\mathrm{C} 1 \mathrm{~L}$ or mutant M71 was compared by predrenching maize seedlings with bacterial suspensions of $1 \times 10^{8}$ CFU per milliliter 1 day before challenging maize leaves with a spore suspension of Cochliobolus heterostrophus $\mathrm{CH} 1$ at $1 \times 10^{4}$ spores per milliliter. Water was used instead of bacterial suspension as a control treatment (CK). Disease symptoms were photographed and were scored 2 days after fungal inoculation. The data from five repeats are presented as the means \pm standard deviation and were compared using one-way analysis of variance followed by Fisher's least significant difference test (an asterisk [*] indicates $P<$ $0.05)$. Bar $=2 \mathrm{~cm}$. 
$1 \times 10^{8} \mathrm{CFU} / \mathrm{ml}$ were $7.17 \times 10^{6}$ and $6.11 \times 10^{5} \mathrm{CFU}$ per gram of roots, respectively (Fig. 2A). The endophytic populations of B. cereus $\mathrm{C} 1 \mathrm{~L}$ and mutant $\mathrm{M} 71$ in maize roots at 5 days after drenching with bacterial suspension of $1 \times 10^{9} \mathrm{CFU} / \mathrm{ml}$ were $2.15 \times 10^{5}$ and $9.73 \times 10^{2} \mathrm{CFU}$ per gram of roots, respectively (Fig. 2B). These results indicated that the root surface and endophytic populations of mutant M71 were severely decreased approximately 11- and 220-fold, respectively, much lower than those of the wild-type $B$. cereus C1L. Next, the surface and endophytic distribution of $B$. cereus $\mathrm{C} 1 \mathrm{~L}$ and mutant M71 in maize roots were observed using confocal microscopy and fluorescence staining of SYTO 9 and Calcofluor White MR2 to label the bacterial cells and cellulose in the plant cell wall, respectively. After coincubation with $B$. cereus $\mathrm{C} 1 \mathrm{~L}$, numerous spot-like bacterial colonies marked by intense bright-yellow signals of SYTO 9 were found on the root surface and inside the roots. Interestingly, B. cereus $\mathrm{C} 1 \mathrm{~L}$ formed more endophytic colonies in vascular bundles than in the cortex (Fig. 2C). By contrast, mutant M71 formed fewer colonies that generally had weaker SYTO 9 signals on the root surfaces and were hardly found inside the roots (Fig. 2D). Additionally, no bacterial colony-like SYTO 9-labeled signals appeared in the noninoculated control roots (Fig. 2E). Herein, confocal observation revealed that both the colony densities and cell numbers of $B$. cereus CL1 on the root surface and inside the roots were superior to those of mutant M71, coinciding with the results shown in Figure 2A and B. Taken together, the importance of $p t s G$ in effective root colonization and endophytic distribution of $B$. cereus $\mathrm{C} 1 \mathrm{~L}$ was verified.

\section{The pts $G$ mutant is weakened in glucose-stimulated} growth and enhanced in the utilization of other sugars.

To investigate the involvement of the glucose transporter $\mathrm{EII}^{\mathrm{Glc}}$ in $B$. cereus $\mathrm{C} 1 \mathrm{~L}$ growth and glucose usage, the growth curves of $B$. cereus $\mathrm{C} 1 \mathrm{~L}$ and mutant M71 cultured in nutrientrich lysogeny broth (LB) and minimal M9CA broth containing 0 , 0.1 , or $0.5 \%$ glucose were assayed (Fig. 3A). In LB broth, glucose supplement caused earlier exponential growth and increased the exponential growth rates of both $B$. cereus $\mathrm{C} 1 \mathrm{~L}$ and mutant M71 compared with the glucose-free control. However, B. cereus $\mathrm{C} 1 \mathrm{~L}$ entered the exponential phase earlier than M71 at all assayed glucose concentrations. A similar result was found in
A

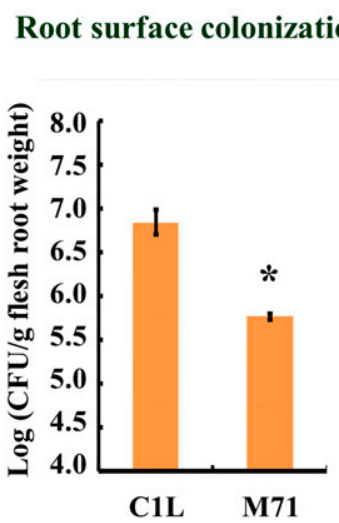

B

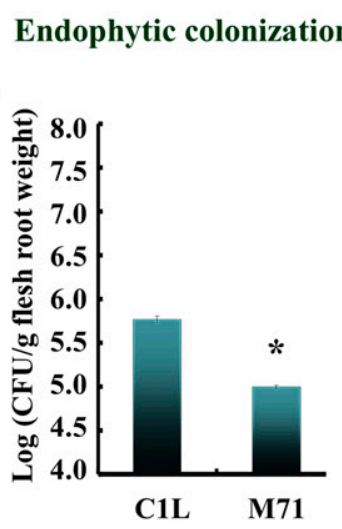

$\mathbf{E}$

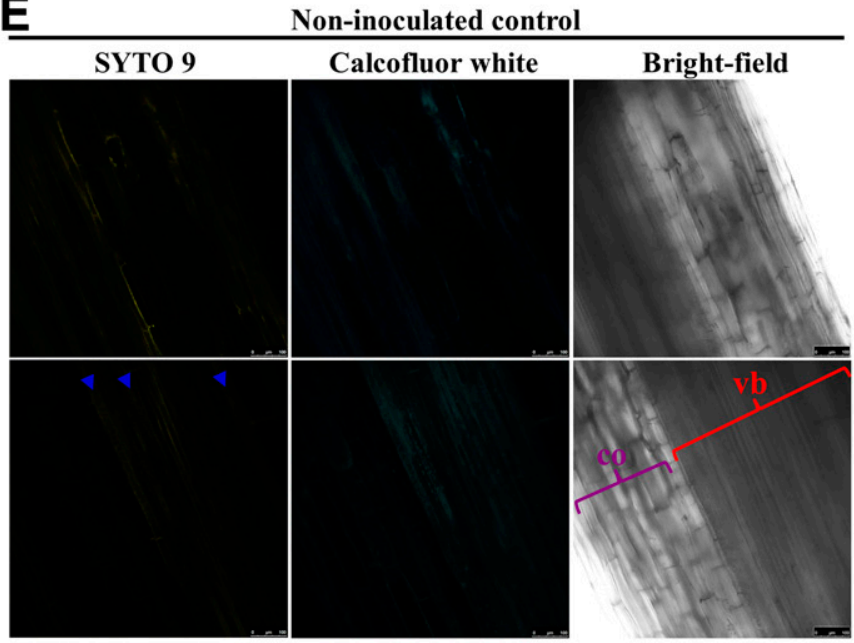

C

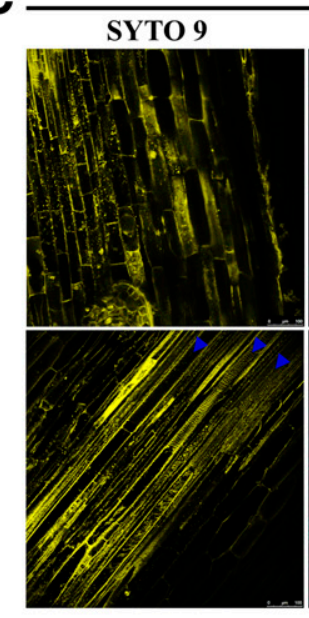

D

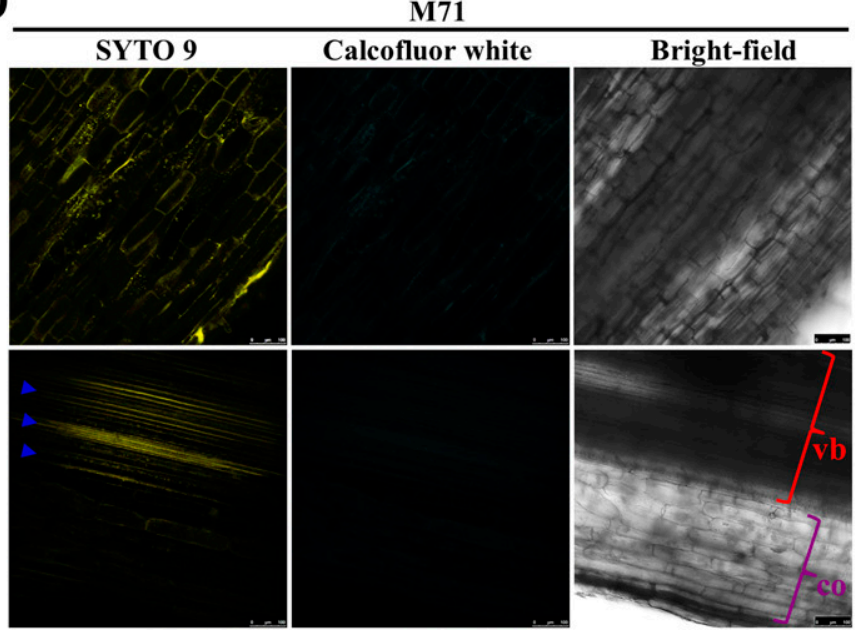

Fig. 2. Population density and distribution of Bacillus cereus $\mathrm{C} 1 \mathrm{~L}$ and mutant $\mathrm{M} 71$ in maize roots were different. $\mathbf{A}$ and $\mathbf{B}$, The bacterial populations of $B$. cereus $\mathrm{C} 1 \mathrm{~L}$ and mutant M71 on the maize root surface and inside the roots were examined with rifampicin-resistant strains and were measured. The data from three repeats are presented as the means \pm standard deviation, compared using analysis of variance followed by the least significant difference test (an asterisk [*] indicates $P<0.05)$. C, D, and $\mathbf{E}$, The distribution of B. cereus $\mathrm{C} 1 \mathrm{~L}$ and mutant M71 in maize roots were visualized by SYTO 9 and Calcofluor White MR2 staining to label the bacteria cells and plant cell walls, respectively. The longitudinal views of the surfaces (upper panels) and cross sections (lower panels) of the primary roots of 7-day-old maize seedlings that germinated in perlites with $B$. cereus $\mathrm{C} 1 \mathrm{~L}$, mutant $\mathrm{M} 71$ at $1 \times 10^{7} \mathrm{CFU} / \mathrm{g}$, or without bacteria (noninoculated control) are shown, respectively. The vascular bundles (vb) and cortex (co) were indicated, and the xylem is indicated by blue arrows. Bar $=$ $100 \mu \mathrm{m}$. 
M9CA broth. Generally, the higher glucose concentrations led to earlier and faster exponential growth, larger maximum bacterial populations and longer population-increasing periods in a $p t s G$ enhanced manner, especially when glucose serves as the major carbon source under nutrient-limited conditions.

To clarify whether $p t s G$ mutation also altered the utilization of other sugars, the growth dynamics of $B$. cereus $\mathrm{C} 1 \mathrm{~L}$ and mutant M71 in LB broth and M9CA broth with or without $0.5 \%$ glucose, fructose, or maltose were compared (Fig. 3B). In LB broth, all three tested sugars resulted in similar growth curves of $B$. cereus $\mathrm{C} 1 \mathrm{~L}$; however, fructose and maltose treatments enabled both $B$. cereus $\mathrm{C} 1 \mathrm{~L}$ and mutant M71 to accumulate more biomass, whereas glucose treatment only greatly enhanced B. cereus $\mathrm{C} 1 \mathrm{~L}$ growth. In M9CA broth, mutant M71 grew better in fructose and maltose treatments than in glucose treatment, which was favored by $B$. cereus $\mathrm{C} 1 \mathrm{~L}$. Thus, $p t s G$ deficiency in $B$. cereus $\mathrm{C} 1 \mathrm{~L}$ changed the preferential utilization of glucose to fructose and maltose in this case.

\section{Certain carbohydrate constituents of root exudate can enhance $p t s G$ expression.}

Glucose, a common constituent of plant root exudates (Badri and Vivanco 2009; Gunina and Kuzyakov 2015; Hütsch et al. 2002; Whipps 1990), can serve as a PTS substrate and a chemoattractant as well as increase $p t s$ operon expression (De Reuse and Danchin 1991; De Reuse et al. 1992), implying that certain constituents of maize root exudates that can enhance ptsGHI operon expression in $B$. cereus $\mathrm{C} 1 \mathrm{~L}$ may either serve as substrates, affect bacterial movement for root colonization, or both.
To identify the functional constituent candidates, the ptsGHI promoter response to whole maize root exudate and individual compositions were assayed using an established green fluorescent protein (GFP) reporter system (Supplementary Fig. S4). Carbohydrate-starved B. cereus C1L harboring the pAD123PptsG reporter with a ptsGHI promoter-driven $G F P$ cassette emitted strong fluorescence in the minimal medium without maize root exudate (CK), and the application of maize root exudate led to an even higher florescent level (Fig. 4A). By contrast, carbohydrate-starved $B$. cereus $\mathrm{C} 1 \mathrm{~L}$ harboring the control vector pAD123 lacking a promoter to express GFP showed only very few fluorescence emissions, which were considered a background noise in both assayed media. Consequently, the response of the ptsGHI promoter to each constituent of maize root exudate (Fan et al. 2012) was assayed, and the carbohydrates of glucose, maltose, isomaltose, mannose, and trehalose at $1 \%$ were found to effectively activate the ptsGHI promoter (Fig. 4B), whereas all assayed organic acids and amino acids at $0.5 \%$ were not (Supplementary Fig. S5). The results indicate that ptsGHI of B. cereus $\mathrm{C} 1 \mathrm{~L}$ is well-expressed in a nutrient-limited environment and can be transcriptionally enhanced while encountering certain carbohydrates of root exudate that may act as recruitment signals from the host plant.

\section{The impaired root colonization of $p t s G$ mutant likely results from the reductions in glucose uptake and consequent glucose chemotaxis.}

To confirm the substrate-dependent involvement of pts $G$ in guiding $B$. cereus $\mathrm{C} 1 \mathrm{~L}$ to the root for colonization, the
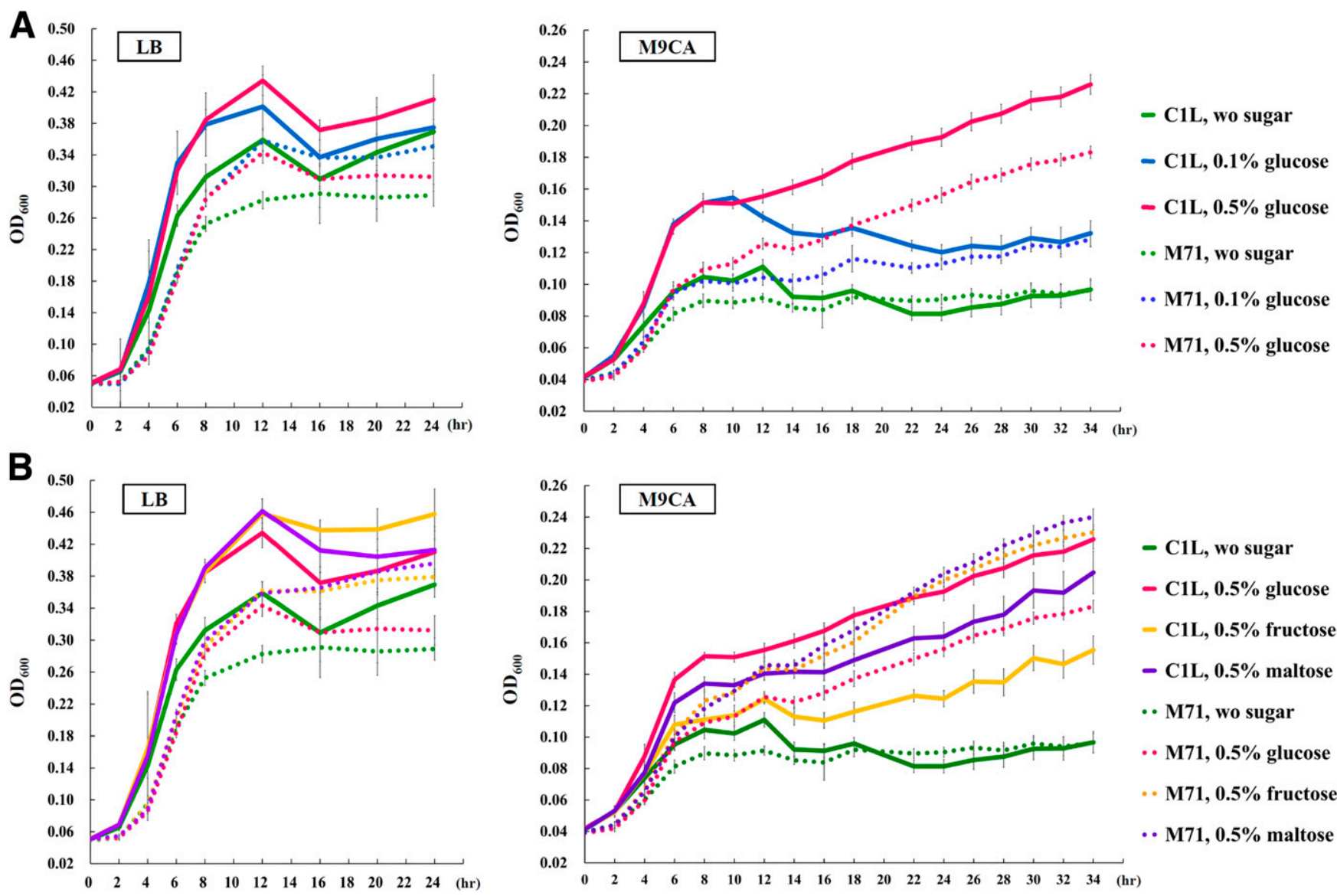

Fig. 3. Growth curves of Bacillus cereus $\mathrm{C} 1 \mathrm{~L}$ and mutant $\mathrm{M} 71$ are affected by medium richness and type of applied sugars. B. cereus $\mathrm{C} 1 \mathrm{~L}$ and mutant $\mathrm{M} 71$ were inoculated in rich lysogeny broth (LB) or minimal (M9CA) medium in the absence or presence of $\mathbf{A}$, glucose at different concentrations or $\mathbf{B}$, different sugars of $0.5 \%$. Bacterial cultures of $150 \mu \mathrm{l}$ were then incubated in 96 -well microtiter plates at $28^{\circ} \mathrm{C}$ with 50 -rpm shaking and were subjected to optical density at $600 \mathrm{~nm}$ $\left(\mathrm{OD}_{600}\right)$ measurement at different timepoints. The data from seven repeats are presented as the means \pm standard deviation. 
chemotaxis of $B$. cereus $\mathrm{C} 1 \mathrm{~L}$ and mutant M71 toward 20x maize root exudate and $0.1 \%$ ptsGHI promoter-inducing carbohydrate constituents, including glucose, maltose, isomaltose, mannose, and trehalose, was compared using sterile deionized water as a reference control. The results showed that, at a starting bacterial concentration of $5 \times 10^{7} \mathrm{CFU} / \mathrm{ml}$, B. cereus C1L exhibited positive chemotactic activities (relative chemotaxis response $[R C R]>2$ ) toward maize root exudate and its carbohydrate constituents of glucose, maltose, and trehalose; however, mutant M71 was only attracted by root exudate poorly $(\mathrm{RCR}=2.07)$ and was not recruited by all of the assayed carbohydrate constituents (Fig. 5A and B). Notably, glucose, the expected substrate of EII ${ }^{\mathrm{Glc}}$, was the most effective attractant among these responsive carbohydrate constituents for B. cereus C1L (Fig. 5B). Additionally, a positive correlation between the glucose concentrations and attracted population of $B$. cereus C1L but not mutant M71 was found, as assayed at a starting bacterial concentration of $1 \times 10^{8} \mathrm{CFU} / \mathrm{ml}$, and the treatment of $128.6 \mu \mathrm{M}$ glucose, equivalent to that in $2 \times$ maize root exudate, still effectively recruited $B$. cereus $\mathrm{C} 1 \mathrm{~L}$ (Fig. 5C). Interestingly, the chemotactic activity toward $0.1 \%$ glucose of $B$. cereus $\mathrm{C} 1 \mathrm{~L}$ could also be increased by a higher starting bacterial concentration (Fig. 5B and C). These findings indicated that ptsGmediated chemotactic attraction of $B$. cereus $\mathrm{C} 1 \mathrm{~L}$ toward glucose was enhanced while the bacterial population, glucose concentration, or both increased. Therefore, the importance of $p t s G$ in the glucose chemotaxis of B. cereus $\mathrm{C} 1 \mathrm{~L}$ for root colonization was demonstrated.

To examine whether $p t s G$ participates in the glucose chemotaxis of $B$. cereus $\mathrm{C} 1 \mathrm{~L}$ via mediating glucose uptake, the glucose consumption of $B$. cereus $\mathrm{C} 1 \mathrm{~L}$ and mutant M71 were assessed. The rate of glucose consumption by carbohydratestarved B. cereus $\mathrm{C} 1 \mathrm{~L}$ at $90 \mathrm{~s}$ after $1 \%$ glucose treatment was $2.48 \mathrm{mg} / \mathrm{ml}$, approximately 20 -fold higher than that by the mutant M71 $(0.12 \mathrm{mg} / \mathrm{ml})$ (Fig. 5D), indicating the tremendous contribution of pts $G$ in the glucose uptake of $B$. cereus C1L. Next, the pts $G$ expression profiles of B. cereus $\mathrm{C} 1 \mathrm{~L}$ and mutant M71 were compared, using semiquantitative RT-PCR after the carbohydrate-starved bacterial cells were treated with $1 \%$ glucose or sterile distilled water for $1 \mathrm{~h}$. The +61 to +263 and +885 to $+1,163$ EIIC domain-coding regions in $p t s G$ transcripts were chosen as amplified targets, and the latter corresponded to the Tn917acl-interrupted portion of the $p t s G$ gene in mutant M71 genome. Both +61 to +263 and +885 to $+1,163$ regions of $p t s G$ transcripts could be generated from $B$. cereus $\mathrm{C} 1 \mathrm{~L}$ cDNAs, but the latter region failed to be detected in mutant M71 cDNAs (Fig. 5E). Additionally, these amplicon signals were stronger in glucose treatment than in water control. The findings coincided with the defect in expressing full-length $p t s G$ transcripts by mutant M71 shown in Figure 1B, and the glucose-inducible trait of the ptsGHI promoter shown in Figure 4B, although mutant M71 was significantly impaired in the glucose uptake efficiency. Thus, the glucose chemotaxis deficiency in the pts $G$ mutant M71 presumably comes from the failure to express a functional EII $^{\text {Glc }}$ for glucose uptake.

\section{The swimming motility and biofilm formation of $B$. cereus $\mathrm{C} 1 \mathrm{~L}$ are not reduced while $p t s G$ is interrupted.}

Successful colonization of beneficial rhizobacterium includes a series of processes of sensing plant signals, moving toward the root surface for attachment, and forming biofilm for stimulating bacterial aggregation (Zhang et al. 2015). Among these processes, chemotaxis is involved in sensing attractants and then guiding bacteria toward attractants via modulating their swimming behavior (Garrity and Ordal 1995). Accordingly, the swimming motility and biofilm formation ability of B. cereus $\mathrm{C} 1 \mathrm{~L}$ and mutant $\mathrm{M} 71$ were compared to further assess the influence of ptsG on root colonization. The swimming motility of $B$. cereus $\mathrm{C} 1 \mathrm{~L}$ and mutant M71 was evaluated on soft nutrient-rich LB and minimal M9CA media ( $0.3 \%$ agar) in the presence of glucose solutions at different concentrations, $2 \mathrm{~cm}$ away from the bacterial inoculation sites, at 24 and $36 \mathrm{~h}$ postinoculation (hpi), respectively (Fig. 6A). On soft LB medium, B. cereus $\mathrm{C} 1 \mathrm{~L}$ and mutant M71 proliferated into circularly symmetrical round-shaped colonies with similar sizes at the same glucose concentrations, and their colony sizes gradually increased as the glucose concentration decreased. The smaller colony size occurring in treatments of higher glucose concentrations is likely due to diffused glucose serving as an additional nutrient that slowed down colony expansion on nutrient-rich LB medium. On soft M9CA medium, the higher glucose concentrations conversely resulted in the larger colony sizes of both $B$. cereus $\mathrm{C} 1 \mathrm{~L}$ and mutant M71 and conferred
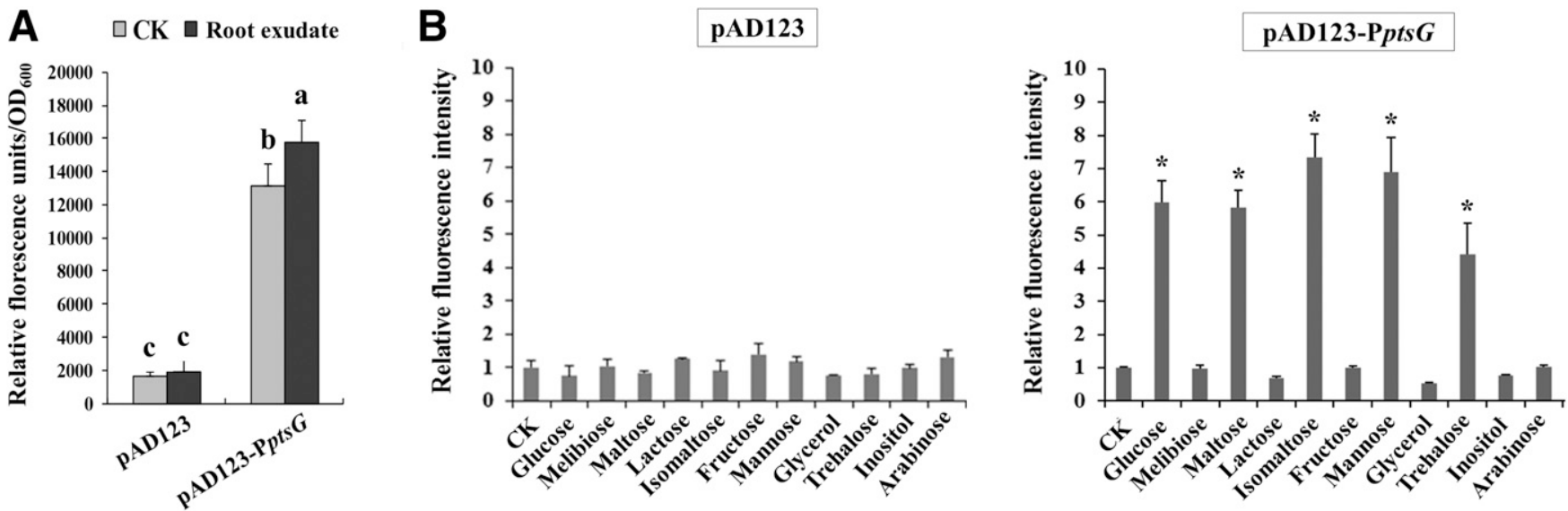

Fig. 4. Inducibility of the Bacillus cereus $\mathrm{C} 1 \mathrm{~L}$ pts $G H I$ promoter to the carbohydrate constituents of maize root exudate. Carbohydrate-starved $B$. cereus $\mathrm{C} 1 \mathrm{~L}$ harboring the reporter vector $\mathrm{pAD} 123-\mathrm{P} p t s G$ with a $p t s G H I$ promoter-driving green fluorescent protein gene $(G F P)$ cassette or control vector pAD123 lacking a promoter to express GFP was inoculated in minimal medium with $\mathbf{A}, 20 \times$ maize root exudate or $\mathbf{B}, 1 \%$ carbohydrate constituents of maize root exudate. Sterile deionized water was used as a control treatment $(\mathrm{CK})$. After $16 \mathrm{~h}$, the optical density at $600 \mathrm{~nm}\left(\mathrm{OD}_{600}\right)$ value and fluorescence intensity (excitation at $485 \mathrm{~nm}$ and emission at $535 \mathrm{~nm}$ ) were recorded to measure the $G F P$ expression level per $\mathrm{OD}_{600}$ unit of cells. The relative fluorescence intensity in B was adjusted based on that of $\mathrm{CK}$. The data from six repeats are presented as the means \pm standard deviation and were compared using analysis of variance followed by the least significant difference test. Means with different letters in A and with asterisks in B are significantly different at the 5\% level. 
greater enhancement on colony expansion of B. cereus $\mathrm{C} 1 \mathrm{~L}$ rather than mutant M71. Additionally, the migration of B. cereus $\mathrm{C} 1 \mathrm{~L}$ toward glucose sources on M9CA became more rapid as glucose concentration increased. By contrast, the colony sizes of $B$. cereus $\mathrm{C} 1 \mathrm{~L}$ and mutant M71 on M9CA in the absence of glucose had no statistically significant difference at 50 hpi. These findings reveal that $B$. cereus $\mathrm{C} 1 \mathrm{~L}$ exhibits faster chemotaxis adaptation toward glucose under nutrient-limited conditions in a $p t s G$-dependent manner to improve its growth and the swimming motility required for the chemotactic movement of $B$. cereus $\mathrm{C} 1 \mathrm{~L}$ is not mechanically impaired as $p t s G$ is mutated.

Biofilm formation of B. cereus $\mathrm{C} 1 \mathrm{~L}$ and mutant $\mathrm{M} 71$ in $\mathrm{LB}$ or $\mathrm{M} 9 \mathrm{CA}$ broth containing $0,0.1$, or $0.5 \%$ glucose was compared using a microtiter-based crystal violet staining method (Fig. 6B). In LB broth, only mutant M71 enhanced biofilm formation when applied with $0.5 \%$ glucose. However, both $B$. cereus $\mathrm{C} 1 \mathrm{~L}$ and mutant M71 formed more biofilm in minimal M9CA broth than in LB broth at all the assayed glucose concentrations, and their biofilm formation levels in M9CA broth seemed to positively correlate with the glucose concentrations. Therefore, the biofilm formation of B. cereus $\mathrm{C} 1 \mathrm{~L}$ is considered to be facilitated while encountering glucose under a carbon-starvation condition and is even stimulated in a nutrient-rich environment as pts $G$ is destroyed. Additionally, a higher biofilm formation level of mutant M71 in response to glucose treatment suggests that its reduction in root colonization ability is not caused by preventing biofilm formation.

\section{The yields of acetoin and 2,3-butanediol are decreased in the pts $G$ mutant.}

Because the lack of functional EII ${ }^{\mathrm{Glc}}$ severely impaired glucose uptake by $B$. cereus $\mathrm{C} 1 \mathrm{~L}$, it may also disturb the subsequent production of glucose metabolites, including some bioactive compounds. Therefore, the metabolites of B. cereus $\mathrm{C} 1 \mathrm{~L}$ and mutant M71 were analyzed using gas chromatography-mass spectrometry (GC-MS) (Gowda and Djukovic 2014; Koek et al. 2006, 2011) to assess the influence of pts $G$ and glucose supplement on the production of secondary metabolites. The supplement of $1 \%$ glucose in LB broth was found to result in two more compounds appearing in the culture supernatant of $B$. cereus $\mathrm{C} 1 \mathrm{~L}$ at retention times of 3.51 and $4.59 \mathrm{~min}$, as detected by GC, compared with glucosefree control (Fig. 7A), and they were identified to be acetoin and 2,3-butanediol, respectively, by subsequent MS analysis against the standard reference database NIST11 (Fig. 7B). Next, the supernatants of $B$. cereus $\mathrm{C} 1 \mathrm{~L}$ and mutant M71 cultured in LB broth with $1 \%$ glucose were compared using GC-MS analysis and acetoin and 2,3-butanediol were shown to be differentially accumulated (Fig. 7C). The concentrations of acetoin and 2,3-butanediol in the supernatant of mutant M71 were measured to be 368 and 209 ppm, respectively, approximately half of those in $B$. cereus $\mathrm{C} 1 \mathrm{~L}$ with the same
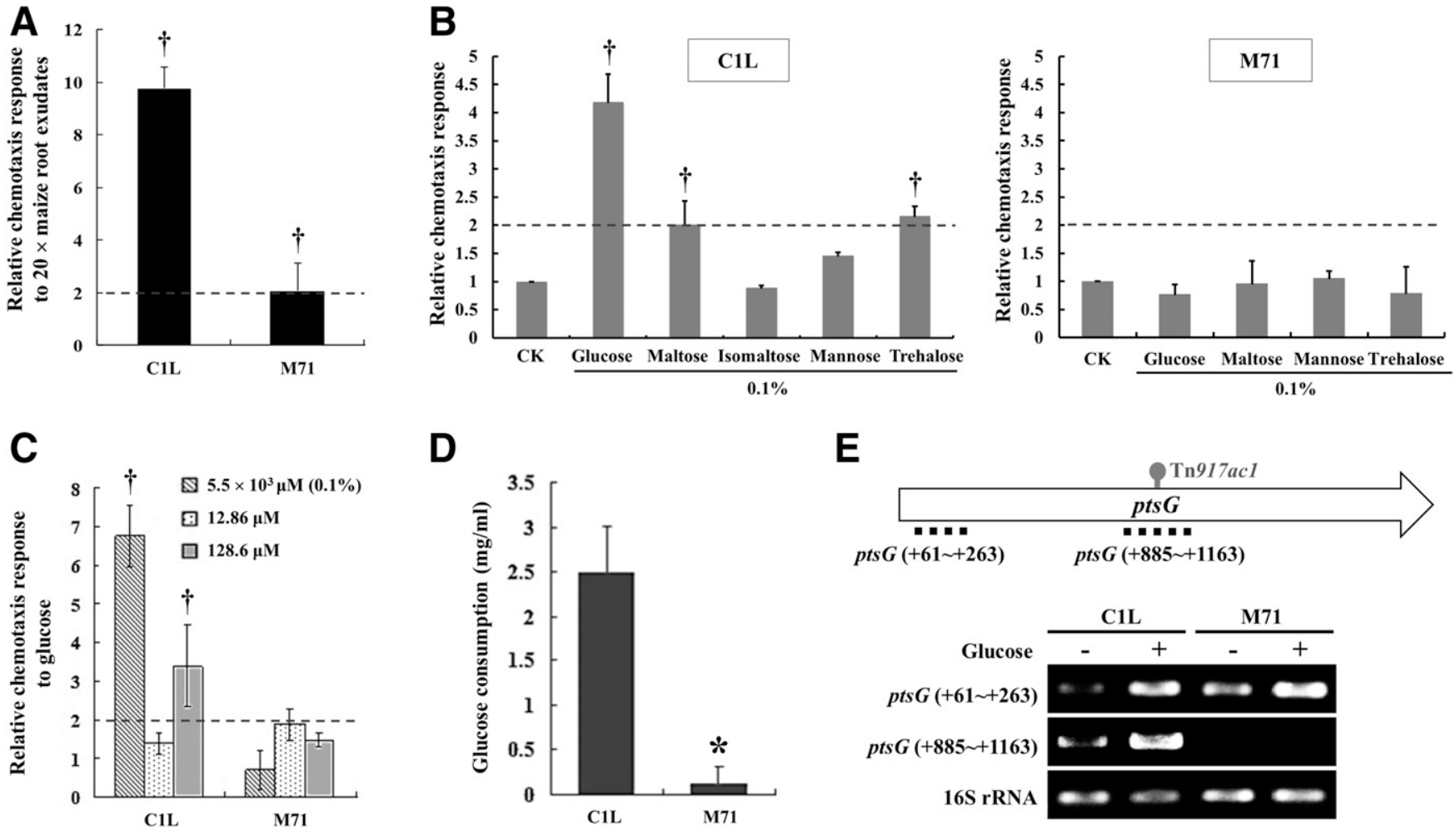

Fig. 5. Chemotaxis responses and glucose consumption of Bacillus cereus $\mathrm{C} 1 \mathrm{~L}$ and mutant M71. A and B, The relative chemotaxis responses (RCRs) of carbohydrate-starved B. cereus $\mathrm{C} 1 \mathrm{~L}$ and mutant M71 at $5 \times 10^{7}$ or $\mathbf{C}, 1 \times 10^{8} \mathrm{CFU} / \mathrm{ml}$ to $20 \times$ maize root exudate (A), $0.1 \%$ carbohydrate constituents of maize root exudate (B), and glucose of different concentrations (C). In short, RCR = bacterial counts attracted by test solution divided by bacterial counts attracted by sterile water control $(\mathrm{CK})$. The data from three repeats are presented as the means \pm standard deviation. RCR values greater than 2 (above the horizontal dotted lines) are considered positive chemotaxis responses and are indicated by crosses. D, The glucose consumption of B. cereus C1L and mutant M71 in the culture supernatant was measured using a glucose (HK) assay kit (Sigma-Aldrich Corp.) $90 \mathrm{~s}$ after treatment with $1 \%$ glucose. The data from three repeats are presented as the means \pm standard deviation and were compared using analysis of variance followed by the least significant difference test (an asterisk [*] indicates $P<0.05$ ). E, The pts $G$ expression in carbohydrate-starved B. cereus $\mathrm{C} 1 \mathrm{~L}$ or mutant $\mathrm{M} 71$ at $1 \mathrm{~h}$ after $1 \%$ glucose treatment was compared by semiquantitative reverse transcription-polymerase chain reaction (E). The +61 to +263 and +885 to $+1,163$ regions of $p t s G$ transcripts, corresponding to the $5^{\prime}-$ terminal and middle portions of the $p t s G$ gene, were the detection targets, and the latter portion in the genome of mutant M71 was interrupted by transposon Tn917ac1. The 16S ribosomal RNA served as an amplification and reference control. 
assayed population (Fig. 7D). Three biological replicates for each treatment of individual bacterial strains were used, and the GC-MS analysis results were reproducible. Herein, the deficiency of $p t s G$ that mediates the major glucose uptake of

A
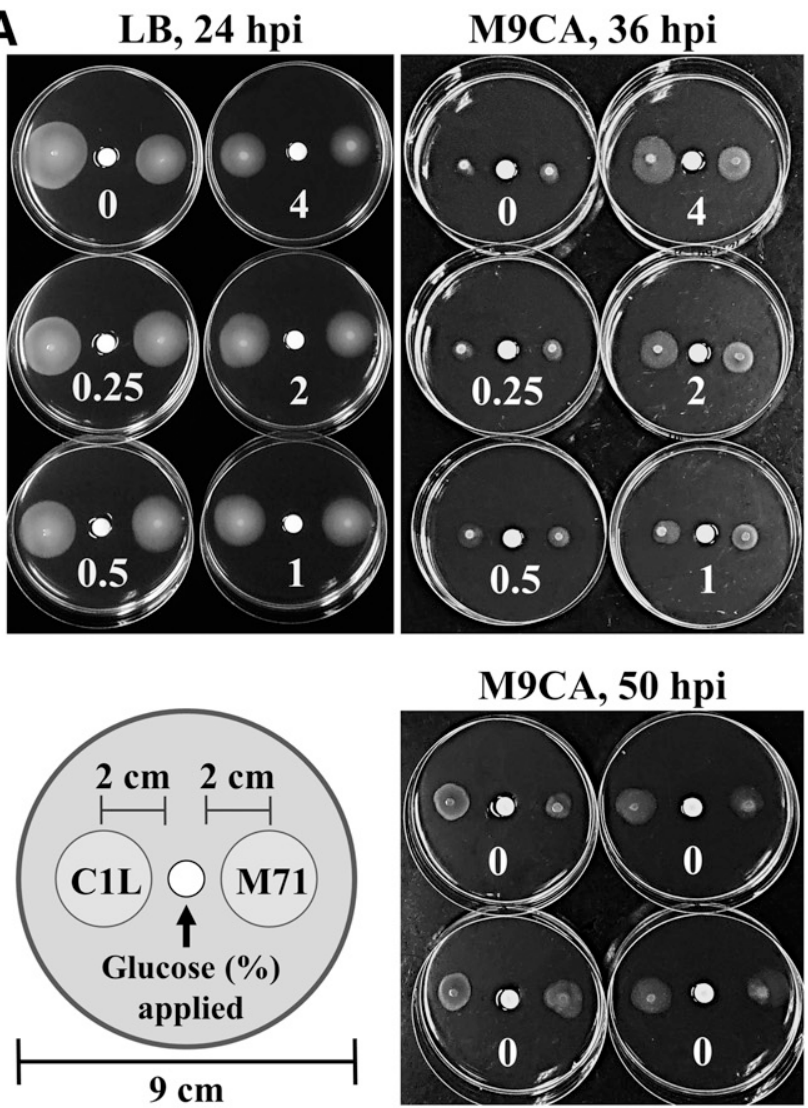

B

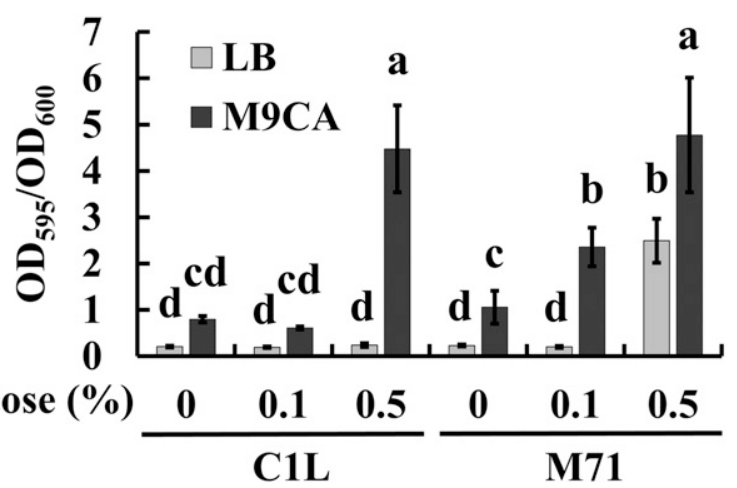

Fig. 6. Swimming motility and biofilm formation of Bacillus cereus $\mathrm{C} 1 \mathrm{~L}$ and mutant M71. A, The swimming motility of B. cereus $\mathrm{C} 1 \mathrm{~L}$ and mutant M71 was assayed on soft lysogeny broth (LB) or M9CA medium $(0.3 \%$ agar). B. cereus $\mathrm{C} 1 \mathrm{~L}$ and mutant M71 were oppositely inoculated on soft LB or M9CA medium $2 \mathrm{~cm}$ away from the filter paper disk soaked with 30 $\mu \mathrm{l}$ of glucose solutions of different concentrations. Pictures were taken at different hours postinoculation (hpi). Four plates were used for each treatment in a single assay, and three repeated assays were performed. $\mathbf{B}$, The biofilm formation of $B$. cereus $\mathrm{C} 1 \mathrm{~L}$ and mutant M71 in LB or M9CA broth with different concentrations of glucose was compared using the microtiter plate-based crystal violet staining assay at $34 \mathrm{hpi}$ at $28^{\circ} \mathrm{C}$ with 50 -rpm shaking. The biofilm formation ability was determined by the ratio of optical density at $595 \mathrm{~nm}\left(\mathrm{OD}_{595}\right)$ (biofilm formation quantified by the trapped crystal violet) to $\mathrm{OD}_{600}$ (bacterial biomass measured before crystal violate staining). The data from seven repeats were presented as the means \pm standard deviation and were compared using analysis of variance followed by the least significant difference test. Means with different letters are significantly different at the $5 \%$ level.
B. cereus $\mathrm{C} 1 \mathrm{~L}$ also impedes the production of glucose metabolites of volatile acetoin and 2,3-butanediol.

\section{Acetoin and 2,3-butanediol prevent SCLB via eliciting} plant ISR rather than inhibiting pathogen growth.

Acetoin and 2,3-butanediol are involved in plant-growth promotion and health protection conferred by PGPR (Chung et al. 2016; Fincheira and Quiroz 2018; Kanchiswamy et al. 2015; Sharifi and Ryu 2018). To identify the action mode of acetoin and 2,3-butanediol in biocontrol conducted by B. cereus $\mathrm{C} 1 \mathrm{~L}$, their ISR-eliciting ability and pathogen inhibitory activity were evaluated. In the ISR assay, maize seedlings were drenched with acetoin or 2,3-butanediol solutions of 0.01 to $10 \mathrm{mM}$ immediately after the foliar challenge of $C$. heterostrophus and the disease severity was surveyed 2 days later. Acetoin drenches of all assayed concentrations were found to suppress SCLB by 20 to $33 \%$, and their protection effects were determined to be statistically identical (Fig. 8A). Interestingly, a 2,3-butanediol drench of $0.1,1.0$, or $10 \mathrm{mM}$ provided SCLB suppression efficacies of 20.49 to $26.04 \%$, which statistically differed from the useless treatments of $0.01 \mathrm{mM}$ 2,3-butanediol and water (CK) (Fig. 8B). These results proved the ISR-eliciting function of acetoin and 2,3butanediol in maize and suggests a higher ISR-eliciting activity of acetoin than 2,3-butanediol, at least in the maize-SCLB system.

The inhibitory activity of acetoin and 2,3-butanediol against pathogen growth was investigated using a divided Petri plate assay. The colony diameter and morphology of $C$. heterostrophus were not altered by the fumigation of acetoin or 2,3-butanediol, as compared with water treatment (CK) (Fig. 8C and D), revealing that both acetoin and 2,3-butanediol could not directly suppress SCLB pathogen growth. Herein, the glucose metabolites of volatile acetoin and 2,3-butanediol are presumed to function as ISR-eliciting compounds but not as antimicrobials in the biocontrol conducted by $B$. cereus $\mathrm{C} 1 \mathrm{~L}$, at least in maizeSCLB system.

\section{B. cereus $\mathrm{C} 1 \mathrm{~L}$ and glucose metabolites of acetoin and 2,3-butanediol systemically activate the maize defense against SCLB.}

To explore the biochemical evidence for the ISR-eliciting ability of $B$. cereus $\mathrm{C} 1 \mathrm{~L}$ and glucose metabolites of acetoin and 2,3-butanediol, plant necrotic cell death caused by SCLB and defense responses against $C$. heterostrophus infection were detected after pathogen inoculation (Fig. 9). At 16 hpi, the trypan blue-stained necrosis lesions caused by C. heterostrophus obviously occurred in the leaves of control treatment $(\mathrm{CK})$ but were seldom found in the leaves of B. cereus $\mathrm{C} 1 \mathrm{~L}$, mutant $\mathrm{M} 71$, acetoin, and 2,3-butanediol treatments. At $48 \mathrm{hpi}$, numerous necrosis lesions distributed evenly throughout the leaves of control treatment; however, at the same time, only very few necrotic lesions were shown in the leaves of the other four treatments and B. cereus $\mathrm{C} 1 \mathrm{~L}$ treatment showed the best efficacy to prevent necrosis lesion formation (Fig. 9A).

Next, reactive oxygen species (ROS) accumulation and callose deposition in the inoculated leaves were accordingly detected to measure the maize systemic defense against $C$. heterostrophus infection. The diaminobenzidine tetrahydrochloride (DAB) staining result at 48 hpi showed that ROS accumulation was strongest in the leaves of $B$. cereus $\mathrm{C} 1 \mathrm{~L}$ treatment, weaker in the leaves of mutant M71, acetoin, and 2,3-butanediol treatments, and almost absent in the leaves of control treatment (Fig. 9B). Similarly, callose was found to deposit around $C$. heterostrophus spores in the leaves of $B$. cereus $\mathrm{C} 1 \mathrm{~L}$ treatment at $16 \mathrm{hpi}$, but almost no callose was 
deposited and more spores had germinated in the leaves of the other treatments at the same timepoint (Fig. 9C). In addition, the microscopic views of trypan blue staining revealed that leaf cells surrounding the germinating spores in the control treatment had died at $16 \mathrm{hpi}$, but those leaf cells in the other treatments were alive, coinciding with the macroscopic views shown in Figure 9A. At 24 hpi, callose-rich papillae had formed in front of the inflated hyphal tips of $C$. heterostrophus to arrest fungal invasion in the leaves of all treatments, except the control treatment, in which callose seldom deposited; additionally, leaf cell death caused by $C$. heterostrophus was still observed only in the control treatment and even became more severe than that at $16 \mathrm{hpi}$. At $48 \mathrm{hpi}$, the callose deposition level in the leaves against $C$. heterostrophus was enhanced with B. cereus $\mathrm{C} 1 \mathrm{~L}$ treatment but remained constant in acetoin, 2,3butanediol, and control treatments and decreased in mutant M71 treatment compared with the callose deposition level at 24 hpi. Additionally, the necrosis levels of all treatments at 48 hpi were consistent in the macroscopic and microscopic views (Fig. 9A and $\mathrm{C}$, respectively). These observations indicated that B. cereus $\mathrm{C} 1 \mathrm{~L}$, mutant M71, acetoin, and 2,3butanediol could induce maize systemic resistance against
SCLB via stimulating plant defense responses; however, the defense enhancement conducted by $B$. cereus $\mathrm{C} 1 \mathrm{~L}$ was the fastest, strongest, and most long-lasting, leading to its best biocontrol efficiency.

\section{DISCUSSION}

Beneficial rhizobacteria play important roles in plant health promotion via diverse mechanisms and have been applied to improve agricultural production for years (Gouda et al. 2018; Mhlongo et al. 2018). B. cereus C1L is a PGPR and ISRmediating rhizobacterial strain isolated from the Lilium rhizosphere and is useful for disease control in both dicot and monocot plants (Huang et al. 2010, 2012a and b, 2017; Lai et al. 2016; Liu et al. 2008). The ISR-eliciting activity of B. cereus $\mathrm{C} 1 \mathrm{~L}$ in many plants strongly suggests that $B$. cereus $\mathrm{C} 1 \mathrm{~L}$ can create a mutually beneficial relationship with different plant species through recognizing some common signals released from plant roots. The signals probably recruit the desired soil microbes, moving toward and colonizing the roots, and then feeding back with bacterial components and compounds beneficial to plant health. In this study, we proved that glucose, the
A
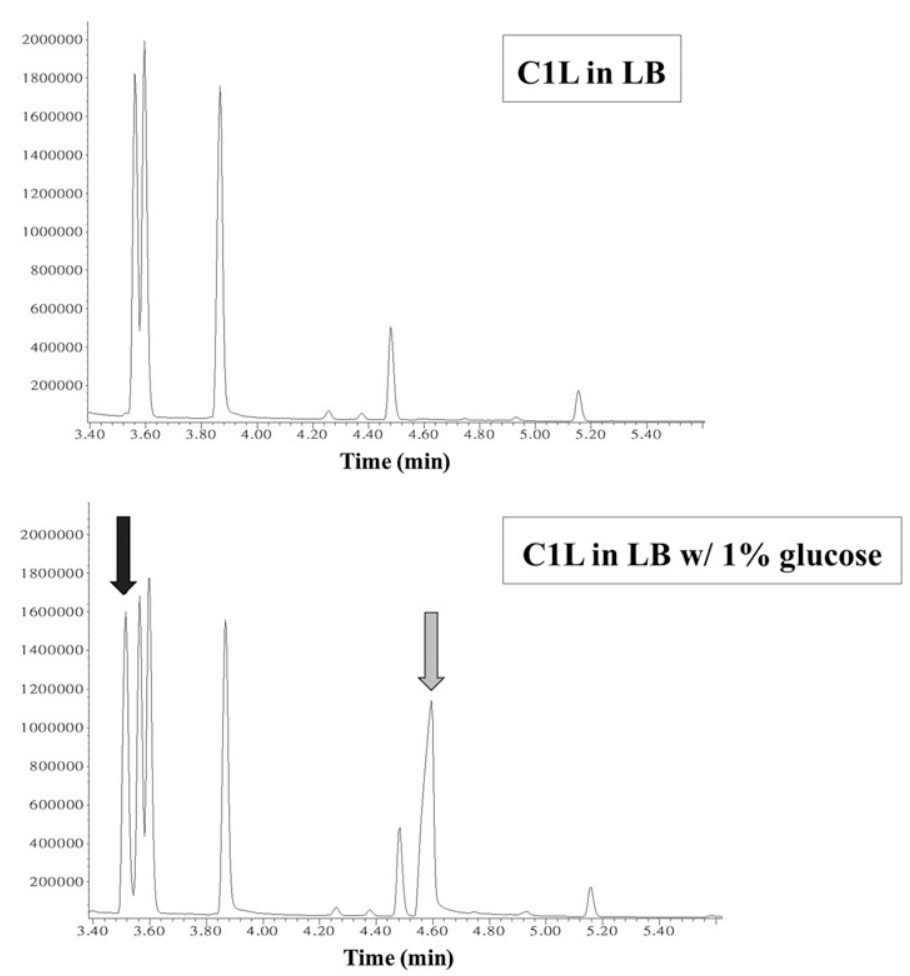

B
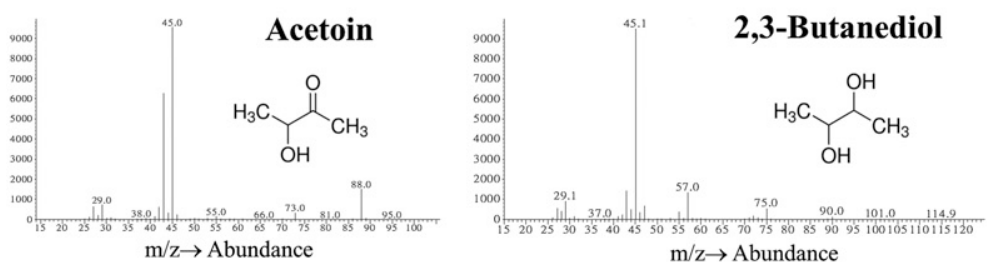
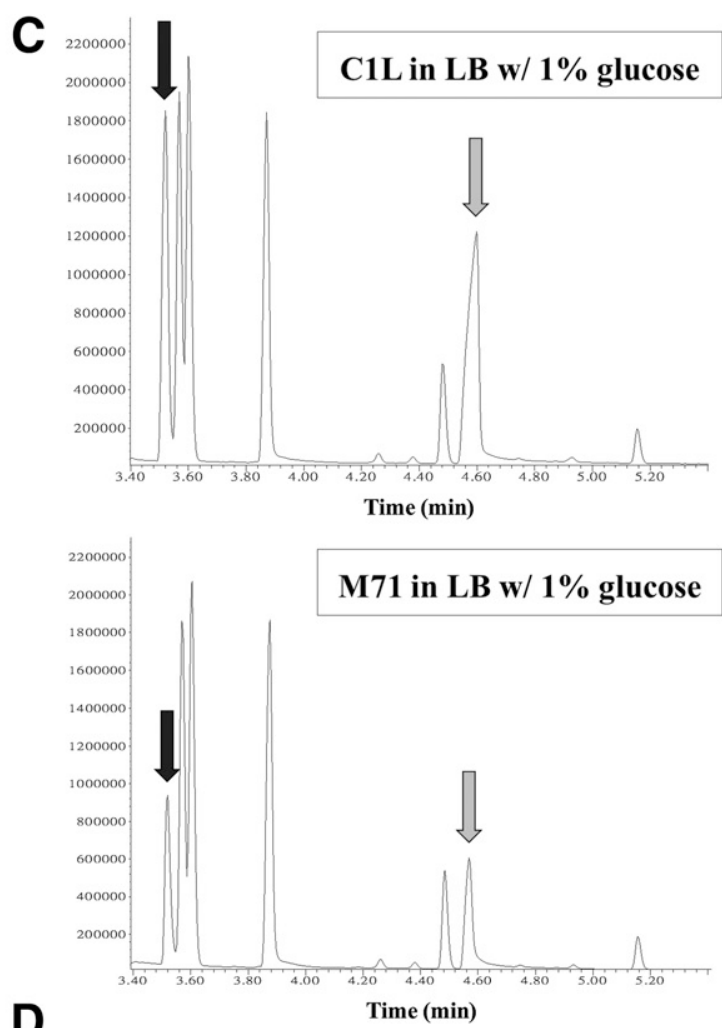

D

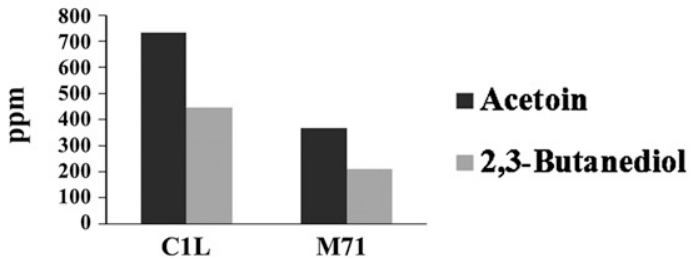

Fig. 7. Comparison of acetoin and 2,3-butanediol production by Bacillus cereus $\mathrm{C} 1 \mathrm{~L}$ and mutant $\mathrm{M} 71$. A, The culture supernatants of B. cereus $\mathrm{C} 1 \mathrm{~L}$ in lysogeny broth (LB) broth only or with the addition of $1 \%$ glucose were diluted with LB broth to a final optical density at 600 nm of 2 , followed by extraction with ethyl acetate and analysis by gas chromatography (GC). B, The differentially secreted substances appearing at retention times of 3.51 and 4.59 min were indicated by the black and gray arrows and were identified as acetoin and 2,3-butanediol by mass spectrometry. C, Acetoin and 2,3-butanediol in the culture supernatants of B. cereus $\mathrm{C} 1 \mathrm{~L}$ and mutant M71 in LB broth containing $1 \%$ glucose were measured by GC as described above and are indicated by the black and gray arrows, respectively. D, The relative amounts of acetoin and 2,3-butanediol from B. cereus $\mathrm{C} 1 \mathrm{~L}$ and mutant $\mathrm{M} 71$ in $\mathrm{C}$. Three biological replicates of the GC-mass spectrometry assay were used for each treatment of individual bacterial strains, and one of the results is shown. 
most common and abundant constituent of root exudates (Badri and Vivanco 2009; Gunina and Kuzyakov 2015; Hütsch et al. 2002; Whipps 1990), serves as a key recruiting signal for $B$. cereus $\mathrm{C} 1 \mathrm{~L}$ from plants, and bacterial $p t s G$ plays a critical role in building a mutually beneficial relationship with plants. The glucose uptake-mediating $p t s G$ determines successful root colonization and subsequent production of bioactive glucose metabolites, i.e., acetoin and 2,3-butanediol, by B. cereus $\mathrm{C} 1 \mathrm{~L}$ for ISR establishment and plant growth promotion, which has been described for PGPR in various plant species (Chung et al. 2016; Fincheira and Quiroz 2018; Kanchiswamy et al. 2015; Sharifi and Ryu 2018). The study on the removal of pyrene pollution in soil using artificial root exudates indicated that glucose application provided the highest cleaning efficiency via recruiting pyrene-degrading bacteria, among which Bacillus spp. were dominant throughout the whole assay lasting three weeks (Lu et al. 2017), similar to our finding in the root colonization of ISR-mediating B. cereus $\mathrm{C} 1 \mathrm{~L}$, which was triggered by host-released glucose. This is the first report to demonstrate that $p t s G$ is involved in the bacterial elicitation of plant ISR and how it works, explaining the mechanism of glucose-related give-and-take interaction, presumably widely adopted in plantrhizosphere microbe mutualisms.

ISR elicitation by rhizobacterium Bacillus spp. highly relies on successful root colonization, which includes a series of processes of sensing plant signals, moving to the root surface, and forming biofilm (Choudhary and Johri 2009). In strain SQR9 of Bacillus amyloliquefaciens, a closely related species of $B$. cereus, the ISR-related biofilm formation can be stimulated by maize root exudate and its individual components, including glucose, citric acid, and fumaric acid, among which glucose may function via the mechanism of bacterial growth promotion. Additionally, the genes involved in PTS and other sugar transport systems, chemotaxis, and flagella synthesis of B. amyloliquefaciens SQR9 are upregulated at $24 \mathrm{hpi}$ and are downregulated at $48 \mathrm{hpi}$ (Zhang et al. 2015). These features of B. amyloliquefaciens SQR9 highly recommend that glucose PTS is involved in the early stage of root colonization to achieve ISR elicitation by Bacillus spp. In this study, the lack of $p t s G$ in $B$. cereus $\mathrm{C} 1 \mathrm{~L}$ causing the reductions of glucose uptake and chemotaxis, glucose-assisted growth, root colonization, bioactive glucose metabolite production, and ISR elicitation but not impeding the swimming motility and biofilm formation was demonstrated to uncover the action mechanisms of glucosespecific EII permease on ISR elicitation. Interestingly, we found that a ptsG complementation strain of mutant M71, which harbored a recombinant pHY300PLK vector with a cassette of ptsGHI promoter and ptsG gene cloned from B. cereus $\mathrm{C} 1 \mathrm{~L}$, could fully restore the ISR-eliciting activity against SCLB and chemotactic toward glucose but partially resumed colonization ability on maize roots. This $p t s G$ complementary strain had a root-surface population 2.5 times higher than mutant M71 but 4.8 times lower than B. cereus C1L. As regards endophytic population, the pts $G$ complementary strain was 10 times higher than mutant M71 but 26 times lower than B. cereus $\mathrm{C} 1 \mathrm{~L}$. These observations suggested that some root colonization-related regulations impeded in mutant M71 might not be compensated by the transcomplement of $p t s G$ gene. However, the root colonization level of this $p t s G$ complementary strain and the subsequent bacterial stimulation
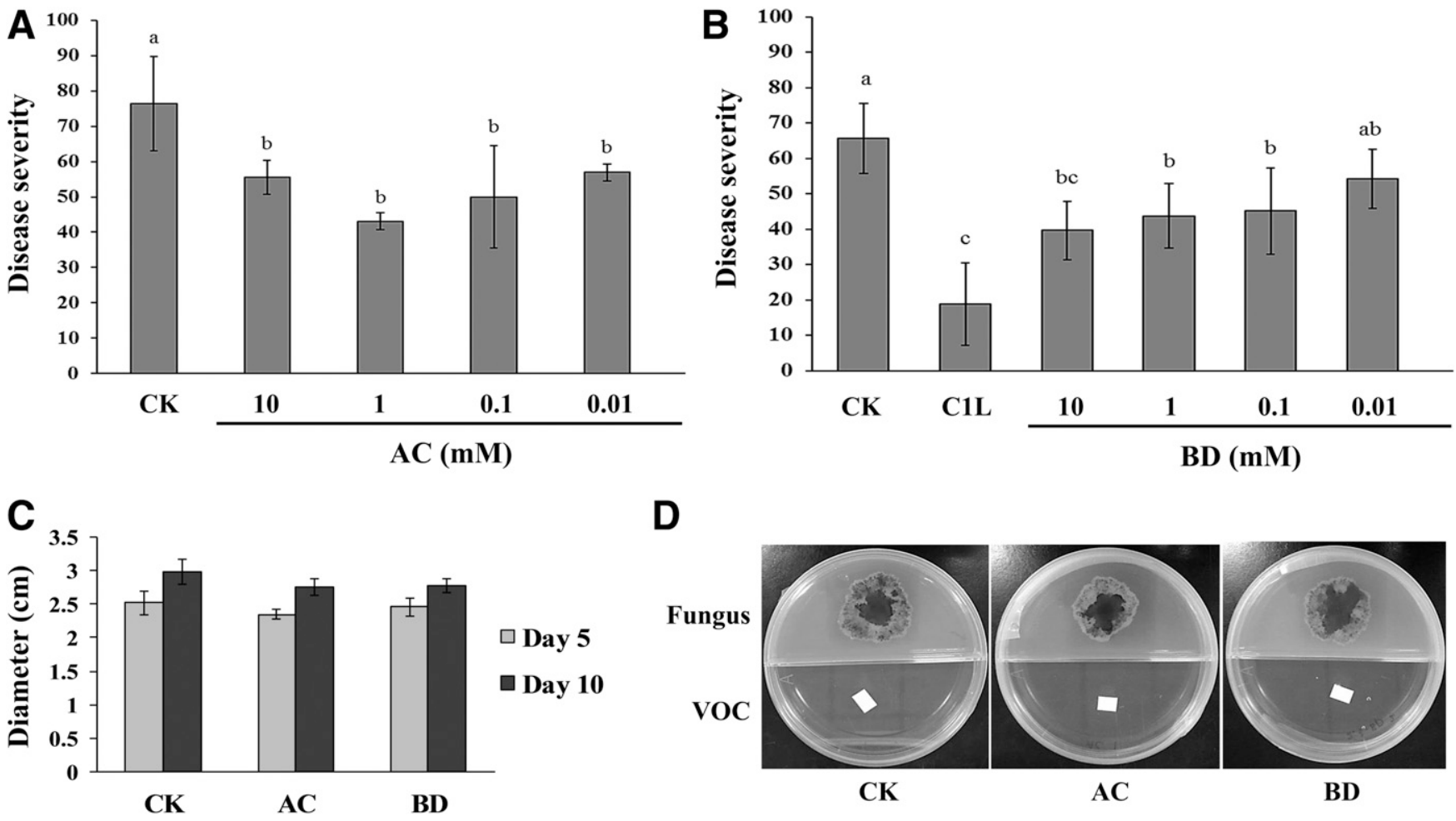

Fig. 8. Effect of acetoin and 2,3-butanediol on the symptom development of southern corn leaf blight and in vitro growth of the fungal pathogen Cochliobolus heterostrophus $\mathrm{CH} 1$. Maize seedlings were drenched with $\mathbf{A}$, acetoin (AC) or $\mathbf{B}, 2,3$-butanediol (BD) solution immediately after inoculation with a $5 \times 10^{4}$ spores/ml suspension of $C$. heterostrophus $\mathrm{CH} 1$. Soil drench with water (CK) was used as a negative control. Maize seedlings were drenched with Bacillus cereus $\mathrm{C} 1 \mathrm{~L}$ of $1 \times 10^{8} \mathrm{CFU} / \mathrm{ml}$ at 1 day before inoculation. The disease index was scored 2 days after inoculation. The fungal pathogen $C$. heterostrophus $\mathrm{CH} 1$ was inoculated on the medium and was fumigated with a $20-\mu 1$ solution of $100 \mathrm{mM}$ acetoin or 2,3-butanediol. C, Colony diameter was measured at 5 and 10 days, and $\mathbf{D}$, fungal morphology was photographed 5 days after incubation. Deionized water was used as a control treatment (CK). The data of five repeats in $\mathrm{A}$ and $\mathrm{B}$ and three repeats in $\mathrm{C}$ are presented as the means \pm standard deviation and were compared using analysis of variance followed by the least significant difference test. Means with different letters are significantly different at the 5\% level. 
seemed to be sufficient for ISR elicitation, at least in the maizeSCLB system. The abolishment of pts $G$ expression in $B$. cereus $\mathrm{C} 1 \mathrm{~L}$ caused by a transposon insertion did not impair the expression of downstream ptsH and ptsI genes. The organization of pts genes in Bacillus subtilis, another closely related species of $B$. cereus, includes a ptsGHI operon and a ptsHI operon, and the $p t s G$-deleted mutant of $B$. subtilis enables the expression of ptsH and ptsI (Cabrera-Valladares et al. 2012; Stülke et al. 1997; Tojo et al. 2010). Accordingly, mutant M71 may express $p t s H$ and $p t s I$ by an uncharacterized ptsHI operon promoter of B. cereus predicted between $p t s G$ and $p t s H$ (Fig. 1A). Similar to our finding on $p t s G$, deleting $p t s H$ or $p t s I$ was also known to decrease glucose utilization, root colonization, and ISR elicitation abilities in other $B$. cereus strains originated from wheat rhizosphere (Gao et al. 2017, 2019; Xu et al. 2014). Therefore, the glucose-specific and general components of glucose PTS playing important roles in the glucose utilization and ISRrelated root colonization of $B$. cereus was eventually concluded.

The glucose consumption assay revealed that $p t s G$ governs the major glucose uptake of B. cereus $\mathrm{C} 1 \mathrm{~L}$ and that one or more other uncharacterized glucose uptake systems may also make a small contribution, coinciding with the report on strain 168 of B. subtilis (Cabrera-Valladares et al. 2012). B. subtilis produces at least two other non-PTS glucose-transporter proteins, the glucose/mannose: $\mathrm{H}^{+}$symporter GlcP and glucose uptake protein GlcU, that can import glucose (Jahreis et al. 2008; Paulsen et al. 1998; Xu et al. 2018). Likewise, B. cereus is supposed to be equipped with similar glucose uptake systems. Notably, mutant M71 maintains the production of 2,3-butanediol and its precursor acetoin, two glucose metabolites from anaerobic fermentation, by approximately $50 \%$ compared with $B$. cereus $\mathrm{C} 1 \mathrm{~L}$, but, when they encounter glucose, M71 consumes only $4.8 \%$ as much glucose as B. cereus $\mathrm{C} 1 \mathrm{~L}$ consumes. Because glucose starvation increases $g l c U$ expression in $p t s G$ and ptsGHI mutants of B. subtilis 168 (Cabrera-Valladares et al. 2012) and overexpression of $g l c U$ promotes acetoin production in B. subtilis 168 under micro-oxygen conditions (Xu et al. 2018), some glucose-transporter proteins, such as GlcU, might be responsible for the production of acetoin and 2,3-butanediol, while ptsG is mutated in B. cereus C1L. Additionally, mutant M71 might synthesize these metabolites using the pyruvates converted from monosaccharide sugars other than glucose ( $\mathrm{Ji}$ et al. 2011).

Bacterial chemotaxis is a type of directional movement in response to certain chemical stimuli that guide bacteria toward attractants or away from repellents via modulation of their swimming behavior and is required for the survival of most bacteria living in rapidly changing environments (Garrity and Ordal 1995). The PTS carbohydrate chemotaxis of B. subtilis is mediated by both PTS and methyl-accepting chemotaxis proteins (MCPs); carbohydrate transport via PTS is essential for chemotactic signaling in response to carbohydrates, enabling the MCP-modulated smooth swimming of B. subtilis toward carbohydrate attractants (Garrity and Ordal 1995; Garrity et al. 1998; Kristich et al. 2003). Additionally, the carbohydrate chemotactic signaling in gram-negative Escherichia coli is also stimulated by the signal from carbohydrate PTS (Neumann et al. 2012). Accordingly, the lack of $p t s G$ abolishes the glucose chemotaxis of $B$. cereus $\mathrm{C} 1 \mathrm{~L}$ via interrupting glucose chemotactic signaling awakened by $\mathrm{EII}^{\mathrm{Glc}}$-dependent glucose transport rather than destroying the mechanical function involved in
A

16

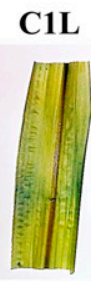
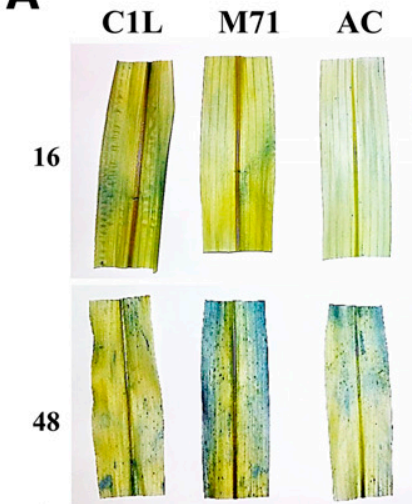

(hpi)

\section{B}

48

(hpi)
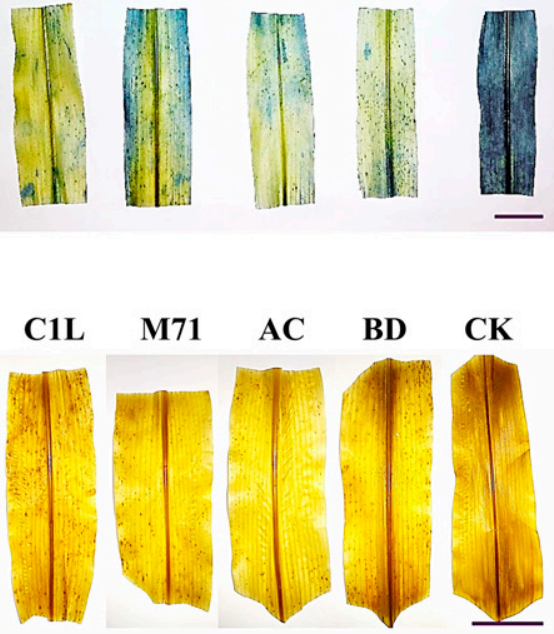
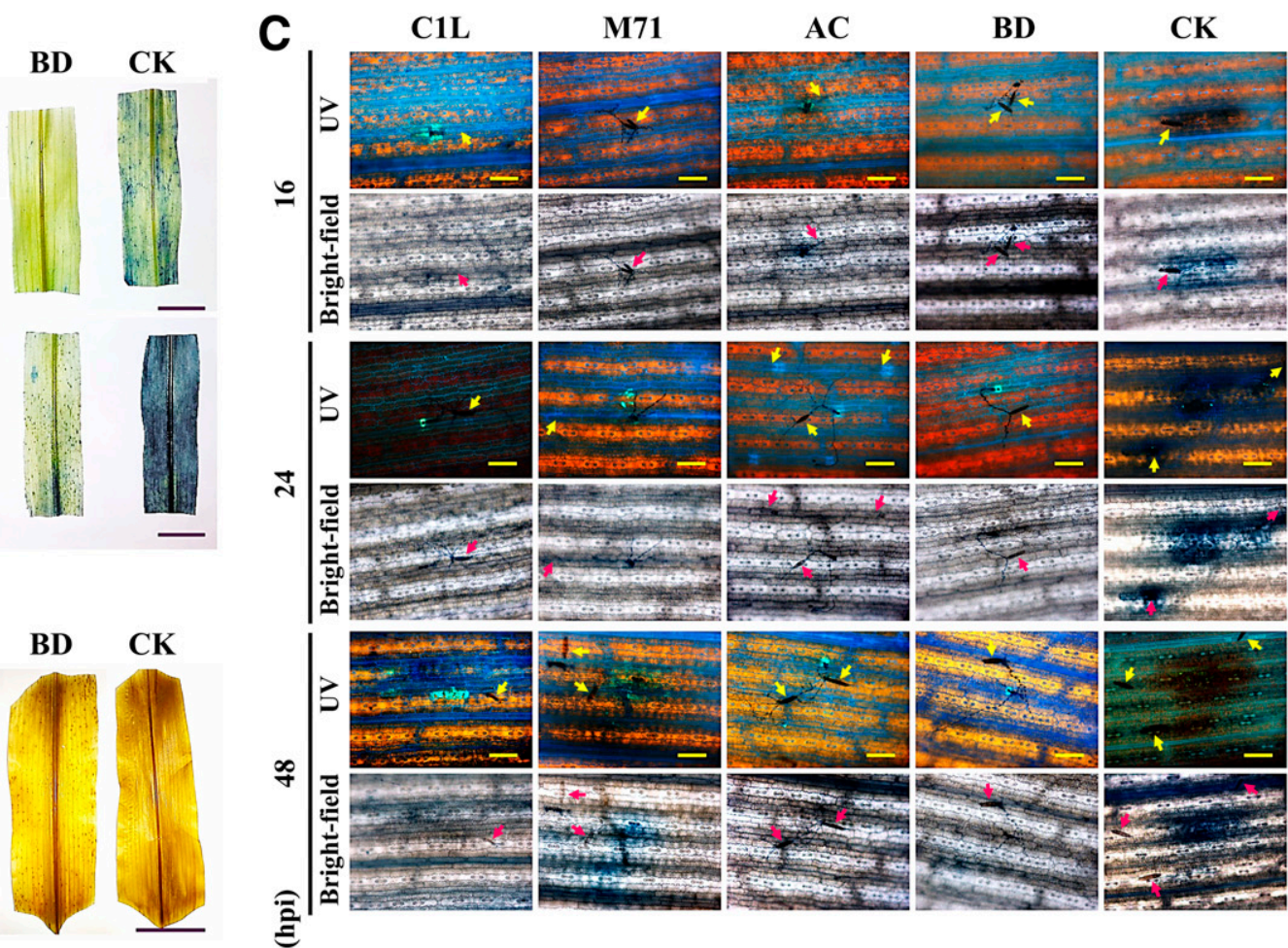

Fig. 9. Predrench of the suspensions of Bacillus cereus C1L and mutant M71 and solutions of acetoin and 2,3-butanediol to maize rhizosphere systemically enhances the leaf defense against southern corn leaf blight (SCLB). Maize seedlings were drenched with $1 \times 10^{8} \mathrm{CFU} / \mathrm{ml}$ suspensions of $B$. cereus $\mathrm{C} 1 \mathrm{~L}$ or mutant M71 or $1 \mathrm{mM}$ solutions of acetoin (AC) or 2,3-butanediol (BD) twice at a 3-day interval. Detached leaves were sprayed with $5 \times 10^{4}$ spores/ml suspension of Cochliobolus heterostrophus $\mathrm{CH} 1$ at 1 day after the last drench. $\mathrm{CK}=$ water treatment. A, SCLB-triggered cell death of maize leaves was observed by trypan blue staining at 16 and $48 \mathrm{~h}$ postinoculation (hpi). B, Accumulation of defense-related reactive oxygen species in leaves was detected by diaminobenzidine tetrahydrochloride staining at 48 hpi. C, Defense-related callose deposition and fungal growth or plant cell death in the leaves were visualized by aniline blue and trypan blue double staining under UV and bright field, respectively, at 16, 24, and 48 hpi. Fungal spores are indicated by arrows. $\mathrm{Bar}=3 \mathrm{~cm}$ in $\mathrm{A}$ and $\mathrm{B}$ and $400 \mu \mathrm{m}$ in $\mathrm{C}$. 
swimming motility, leading to a decrease in the root colonization efficiency.

The rhizosphere is a nutrient-rich region of soil that exhibits great attraction to soil-inhabiting microbes, because the root exudates secreted by plants containing various low-molecular weight organic compounds can serve as a food source for these microbes. Carbohydrates are the most abundant constituents of root exudates and mainly present in the form of monosaccharides. The dominant sugars in root exudates include glucose, fructose, galactose, arabinose, maltose, raffinose, rhamnose, sucrose, and xylose, and the first two make up 40 to $50 \%$ and $23 \%$ of the root exudate sugars, respectively (Badri and Vivanco 2009; Gunina and Kuzyakov 2015; Hütsch et al. 2002; Whipps 1990). In this study, B. cereus C1L exhibited the strongest chemotactic activity toward glucose among all assayed sugar constituents of maize root exudates and grew better in the presence of glucose than fructose and maltose in minimal M9CA broth, whereas the ptsG mutant acted conversely. Bacteria are known to exhibit faster chemotaxis adaptation in nutrient-poor medium, enabling their movement quickly toward a nutrient concentration peak (Zhang et al. 2017). Additionally, chemotaxis and growth were reported to have a coupled effect on accelerating bacterial migration toward a chemoattractant-rich space in which the bacterial population subsequently increases (Wang et al. 2008). Taken together, our findings highly suggest that glucose chemotaxis and preferential utilization of glucose mediated by $p t s G$ cooperatively confer higher competitiveness of $B$. cereus $\mathrm{C} 1 \mathrm{~L}$ for root colonization and very probably lead to the higher abundance of endophytic B. cereus $\mathrm{C} 1 \mathrm{~L}$ in vascular bundles containing glucose-rich phloem tissues.

The glucose application induced a type of submerged, surface-associated biofilm formed by both $B$. cereus $\mathrm{C} 1 \mathrm{~L}$ and mutant M71, and the induction level in mutant M71 was significantly higher than that in $B$. cereus $\mathrm{C} 1 \mathrm{~L}$ at the same glucose concentrations, revealing that $p t s G$ expression has an unexpected inhibitory effect on glucose-induced surfaceassociated biofilm formation. Thus, $p t s G$ deficiency causing a decrease of root colonization efficiency of mutant M71 should not involve the mechanism of impeding biofilm formation. By contrast, the glucose-induced surface-associated biofilm formation level becomes lower in the pts $H$ mutant of wheat rhizosphere-associated B. cereus 905 (Gao et al. 2019). Because $p t s G$ deletion leads to higher expression levels of $p t s H$ and ptsI in B. subtilis 168 (Cabrera-Valladares et al. 2012), the increment in the glucose-induced surface-associated biofilm formation of mutant M71 probably resulted from stronger $p t s H$ expression due to $p t s G$ deficiency. Wheat rhizosphereassociated B. cereus 905 forms two types of biofilms, floating biofilm named pellicles, occurring at the air-liquid interface and submerged, surface-associated biofilm, seemingly via independent mechanisms (Gao et al. 2015). On the one hand, the formation of pellicles in which bacteria undergo dramatic differentiation and continue to proliferate presumably relies on the orthologs of pellicle formation-employed genes of B. subtilis, the model species of biofilm formation (Lemon et al. 2008). On the other hand, the formation of submerged, surface-associated biofilm occurring under glucose fermentation conditions is alternatively induced by a $\mathrm{pH}$ drop resulting from excess glucose application, more in line with biofilm formation of the gram-positive pathogen Staphylococcus aureus, which weakens the host immune responses to achieve successful infection through biofilm formation (Lister and Horswill 2014). The trait of glucose-induced surface-associated biofilm formation accordingly suggests that $B$. cereus $\mathrm{C} 1 \mathrm{~L}$ considers host-released glucose to be not only a chemoattractant but also a stimulator for host-associated biofilm formation, eventually enhancing its root colonization in a $p t s G$-dependent manner.

Certain bacterial volatile organic compounds (VOCs) positively affect plant growth and health via various action mechanisms (Chung et al. 2016; Fincheira and Quiroz 2018; Kanchiswamy et al. 2015; Sharifi and Ryu 2018). B. cereus $\mathrm{C} 1 \mathrm{~L}$ is a PGPR and ISR-mediating rhizobacterium demonstrated to produce bioactive VOCs, including the glucose metabolites of acetoin and 2,3-butanediol in this study as well as dimethyl disulfide described previously (Huang et al. 2012b). These three VOCs are known to promote plant growth and elicit ISR of many plant species (Chung et al. 2016; Fincheira and Quiroz 2018; Huang et al. 2012b; Kanchiswamy et al. 2015; Sharifi and Ryu 2018). Additionally, soil application with 2,3butanediol systemically improves maize attraction to parasitoid Cotesia marginiventris, a natural enemy of the herbivorous larvae of Spodoptera littoralis, probably via altering the composition of the rhizosphere microbial community (D'Alessandro et al. 2014), whereas dimethyl disulfide exhibits inhibitory activity against pests, including bacterial and fungal pathogens as well as nematodes (Sharifi and Ryu 2018). These cases suggest a potential role of $B$. cereus $\mathrm{C} 1 \mathrm{~L}$ in the remodeling of the rhizosphere microbiome via releasing 2,3-butanediol and dimethyl disulfide. Supposedly, these VOC combinations partially contributes to the multifaceted beneficial effects of B. cereus $\mathrm{C} 1 \mathrm{~L}$ on different plant species and the $p t s G$ mutant with lower levels of root colonization and beneficial glucose metabolite production are consequently reduced in ISReliciting ability.

B. cereus $\mathrm{C} 1 \mathrm{~L}$ accumulates more biomass by consuming glucose rather than fructose and maltose, two other PTS sugars, in minimal M9CA broth, whereas mutant M71 conversely preferred fructose and maltose. The pts $G$ mutant of $B$. subtilis 168 was also found to increase growth in fructose-containing minimal medium compared with wild type, which proliferated better in glucose-containing minimal medium (CabreraValladares et al. 2012). Because fructose is the second most abundant sugar of root exudate (Gunina and Kuzyakov 2015; Hütsch et al. 2002), changing the preferential utilization of sugar may partially compensate for the reduction of mutant M71 in root colonization caused by the lack of the major glucose transporter EII ${ }^{\mathrm{Glc}}$. Although mutant M71 imported less glucose, interestingly, the ptsGHI promoter in mutant M71 was found to exhibit higher activity in the absence of glucose and maintain the glucose-inducibility as wild-type B. cereus $\mathrm{C} 1 \mathrm{~L}$, by comparing the transcriptional levels of $p t s G(+61$ to +263$)$ (Fig. 5E). In B. subtilis 168, the glucose-induced transcription of the ptsGHI operon is negatively regulated via the phosphorylation of the PRD1 domain of the antiterminator protein GlcT by EII ${ }^{\text {Glc }}$ in the absence of glucose and, by contrast, is positively regulated via the phosphorylation of the PRD2 domain of GlcT by HPr in a glucose-independent manner (Joyet et al. 2013; Schmalisch at el. 2003). Additionally, ptsG deletion leads to higher expression levels of ptsH and ptsI in B. subtilis 168 (Cabrera-Valladares et al. 2012). Thus, the subtle difference in glucose-mediated $p t s G(+61$ to +263$)$ expression between $B$. cereus $\mathrm{C} 1 \mathrm{~L}$ and mutant $\mathrm{M} 71$ probably results from the fact that mutant M71 lacks ptsG-encoded EII ${ }^{\mathrm{Glc}}$ to suppress the transcriptional activation of the ptsGHI operon during glucose starvation but retains $p t s H$-encoded $\mathrm{HPr}$, which is required for glucose-induced pts $G$ expression. Additionally, the glucoseresponsive regulation of the $p t s G H I$ operon expression is supposed to be highly sensitive, because mutant M71 has much less glucose uptake.

In this study, plant-rhizosphere Bacillus spp. mutualism was found to be achieved via the glucose-related give-and-take interaction mediated by bacterial glucose-specific PTS permease 
EII $^{\mathrm{Glc}}$. This permease participates in root colonization and bioactive glucose metabolite production, which are important for ISR elicitation, expanding our understanding of the mechanism to create such a mutually beneficial relationship for ecofriendly plant protection.

\section{MATERIALS AND METHODS}

\section{Microorganisms.}

Bacillus cereus C1L (Liu et al. 2008) and its mutant M71, E. coli Top10F' (Invitrogen Corp., Waltham, MA, U.S.A.), E. coli GM2163 (Marinus et al. 1983) (New England Biolabs, Ipswich, MA, U.S.A.), and E. coli with pAD123 (Dunn and Handelsman 1999) (Bioresource Collection and Research Center [BCRC] 41796) were used. B. cereus and E. coli strains were cultured in LB broth ( $1 \%$ tryptone, $0.5 \%$ yeast extract, $0.5 \% \mathrm{NaCl}$ ) with shaking at $175 \mathrm{rpm}$ or on LB agar (LB broth with $1.5 \%$ agar) at 28 and $37^{\circ} \mathrm{C}$, respectively. Over 2,000 mutants of $B$. cereus $\mathrm{C} 1 \mathrm{~L}$, including mutant M71, were generated by $\operatorname{Tn} 917 a c 1$ transposition system-based mutagenesis, following the procedure described by Chang et al. (1994) in this study, and they are resistant to chloramphenicol at $10 \mu \mathrm{g} / \mathrm{ml}$. Spontaneous rifampicin-resistant strains of B. cereus $\mathrm{C} 1 \mathrm{~L}$ and mutant M71 were obtained by screening in rifampicincontaining LB medium, and their ISR-inducing ability was surveyed to be identical with the original B. cereus $\mathrm{C} 1 \mathrm{~L}$ and mutant $\mathrm{M} 71$, respectively. SCLB-causing fungus C. heterostrophus $\mathrm{CH} 1$ (race $\mathrm{O}$ ) was cultured on potato dextrose agar (PDA) (Difco Laboratories Inc., Detroit) at $28^{\circ} \mathrm{C}$ for 7 to 14 days for sporulation. The conidiospores were suspended in sterile $0.05 \%$ Tween 20 to a final concentration of $1 \times 10^{4}$ or $5 \times 10^{4}$ spores per milliliter as an inoculum.

\section{Plant cultivation.}

Seeds of maize cv. Honey Jean No. 3 (Known-You Seed Co., Ltd., Kaohsiung, Taiwan) were kept in the dark, at $28^{\circ} \mathrm{C}$ and high humidity, until germination. The seeds were transferred to potting mix containing peat moss, perlite, and vermiculite at a ratio of 2:1:1 ( $\mathrm{vol} / \mathrm{vol} / \mathrm{vol})$. Maize plants were grown in a day and night cycle of 16 and $8 \mathrm{~h}$, respectively, at $28^{\circ} \mathrm{C}$ and a relative humidity of 50 to $60 \%$.

\section{RT-PCR and semiquantitative RT-PCR analysis.}

Total RNA of B. cereus strains was extracted using TriZol reagent (Invitrogen Corp.) and was reverse transcribed to cDNA using the PrimeScript RT reagent kit (Takara Co., Ltd., Shiga, Japan). The PCR cycling conditions included an initial denaturation of $95^{\circ} \mathrm{C}$ for $10 \mathrm{~min}$ followed by several cycles of $95^{\circ} \mathrm{C}$ for $30 \mathrm{~s}, 55^{\circ} \mathrm{C}$ for $30 \mathrm{~s}$, and $72^{\circ} \mathrm{C}$ for 60 or $90 \mathrm{~s}$ and a final extension of $72^{\circ} \mathrm{C}$ for $10 \mathrm{~min}$; the cycle number was 40 or 20 and the cyclic extension step at $72^{\circ} \mathrm{C}$ was for 60 or $90 \mathrm{~s}$ for normal or semiquantitative $\mathrm{PCR}$, respectively. The reaction mixture contained $2 \mathrm{ng}$ of cDNA per microliter, $0.05 \mathrm{U}$ of ProTaq polymerase per microliter (Protech Technology Enterprise Co., Ltd., Taipei, Taiwan), $1 \times$ ProTaq polymerase buffer, $200 \mu \mathrm{M}$ of dNTPs, and $400 \mathrm{nM}$ of primer pairs. The primer pairs are listed in Table 1 . The PCR products were analyzed using agarose gel electrophoresis.

\section{Disease suppression assay.}

Three-week-old maize plants were drenched with a bacterial suspension of $B$. cereus $\mathrm{C} 1 \mathrm{~L}$ or mutant M71 at $1 \times 10^{8}$ $\mathrm{CFU} / \mathrm{ml}$ or a VOC solution of acetoin or 2,3-butanediol solution at different concentrations. The leaves were sprayed with $C$. heterostrophus $\mathrm{CH} 1$ spore suspension 1 day after bacterial suspension treatment or immediately before VOC solution treatment. The inoculated plants were kept moist at $28^{\circ} \mathrm{C}$ with a day and night cycle of 16 and $8 \mathrm{~h}$, respectively, for symptom development, and the disease index was recorded 2 or 3 days later. The disease index of a single seedling was the average of three leaves assessed on a 0 to 5 scale as follows: $0=$ no lesions, $1=1$ to $20 \%$ of the leaf area with lesions, $2=$ 21 to $40 \%, 3=41$ to $60 \%, 4=61$ to $80 \%$, and $5=81$ to $100 \%$. Disease severity $(\%)=[\Sigma($ scale $\times$ number of the leaves in this scale)] / (total number of leaves $\times 5) \times 100 \%$. Five plants were used for each treatment, and the experiment was repeated twice.

\section{Colonization assays.}

To measure the root surface-colonized bacterial population, surface-sterilized maize seeds were aseptically grown in a mixture of perlite and vermiculite at a ratio of $1: 1(\mathrm{vol} / \mathrm{vol})$ at $28^{\circ} \mathrm{C}$ and a relative humidity of 50 to $60 \%$ under a day and night cycle of 16 and $8 \mathrm{~h}$ for 2 weeks. Next, the roots of maize seedlings were dipped with a bacterial suspension of rifampicin-resistant $B$. cereus $\mathrm{C} 1 \mathrm{~L}$ or mutant $\mathrm{M} 71$ at a concentration of $1 \times 10^{8} \mathrm{CFU} / \mathrm{ml}$ for $10 \mathrm{~min}$ and were cultured for 4 more days. The roots were collected and weighed, were placed in M9 medium broth (AMRESCO, Inc., Solon, OH, U.S.A.) $\left(0.6 \% \quad \mathrm{Na}_{2} \mathrm{HPO}_{4} \cdot 7 \mathrm{H}_{2} \mathrm{O}, 0.3 \% \quad \mathrm{KH}_{2} \mathrm{PO}_{4}, 0.05 \% \mathrm{NaCl}, 0.1 \%\right.$ $\mathrm{NH}_{4} \mathrm{Cl}, \mathrm{pH}$ 7.2), and were vortexed at high speed for $10 \mathrm{~min}$. Next, the bacterial counts in the suspension were examined by the dilution plating method-based rifampicin-resistance screening. Three seedlings were used for each bacterial strain.

To measure the endophytic bacterial population, a 4-weekold maize seedling was drenched with $50 \mathrm{ml}$ of the bacterial suspension of rifampicin-resistant $B$. cereus $\mathrm{C} 1 \mathrm{~L}$ or mutant M71 at a concentration of $1 \times 10^{9} \mathrm{CFU} / \mathrm{ml}$, and the bacterial counts inside $0.1 \mathrm{~g}$ of the root tissues were measured 5 days later, as described above, after the root tissues were surface-sterilized

Table 1. The primer pairs used in PCR, reverse transcription PCR, and semiquantitative PCR assays

\begin{tabular}{|c|c|c|}
\hline Target to be amplified & Primer designation & Primer sequence $\left(5^{\prime} \rightarrow 3^{\prime}\right)$ \\
\hline \multirow[t]{2}{*}{$p t s G$} & ptsG-F1 & CTTCCAGTAGCGATTTTACCGGCGGC \\
\hline & ptsG-R1 & CTGAATGTCAATAATAGCGGTTTCGCCC \\
\hline \multirow[t]{2}{*}{ ptsHI } & ptsH2782 & GACTCAGGAATTCATGCTCG \\
\hline & ptsI1401 & GAAGTAATGCACGAAGTTGTG \\
\hline \multirow[t]{2}{*}{ ptsI } & $383 \mathrm{fw} 5$ & CGGAACACCAAATGATGTAC \\
\hline & ptsGHI-R & TAATTCTGTCTCTTATCCTCGATAG \\
\hline \multirow[t]{2}{*}{ 16S rDNA } & $16 \mathrm{~S}-\mathrm{F}$ & CAGCTCGTGTCGTGAGATGT \\
\hline & $16 \mathrm{~S}-\mathrm{R}$ & TGTGGGATTGGCTTAACCTC \\
\hline \multirow[t]{2}{*}{$p t s G(+61$ to +263$)$} & $p t s G(+61)-\mathrm{F}$ & GCGATTTTACCGGCGGAG \\
\hline & $p t s G(+263)-\mathrm{R}$ & CCGTCTCCACCAGCTAAACC \\
\hline \multirow[t]{2}{*}{$p t s G(+885$ to $+1,163)$} & $p t s G(+885)-\mathrm{F}$ & TCTTCCAGCAGCAGCTTTAGC \\
\hline & $p t s G(+1163)-\mathrm{R}$ & CGGCCTGGTAGTACACCG \\
\hline \multirow[t]{2}{*}{$p t s G$ promoter } & $p t s G$ promoter-F & GGGAATTCATCTTCAATATGCTATTGAGAGGGTG \\
\hline & $p t s G$ promoter-R & GGGGATCCAACCCTTCCTCTCTTATCTATATTGATACC \\
\hline
\end{tabular}


with $1 \%$ sodium hypochlorite for $30 \mathrm{~s}$ and pulverized. Three seedlings were used for each bacterial strain in a single assay, and two repeated assays were performed.

To uncover the root surface and endophytic distribution of B. cereus $\mathrm{C} 1 \mathrm{~L}$ and mutant M71, surface-sterilized maize seeds were grown in vermiculite, which was pre-autoclaved and then mixed with bacterial suspension to a final concentration of $1 \times$ $10^{7} \mathrm{CFU}$ per gram, following the procedure described by Roncato-Maccari et al. (2003). Seven days later, the primary roots were collected, were cut into longitudinal sections of 20 to $40 \mu \mathrm{m}$ in thickness by freehand sectioning, were stained with $4 \mu \mathrm{M}$ SYTO 9 (Invitrogen Corp.) and 0.3\% Calcofluor White MR2 (Sigma-Aldrich Co., St. Louis), in the dark for $60 \mathrm{~min}$, to label the bacterial cells and plant cell walls, respectively. Next, the sections were observed under a Leica TCS SP5 II confocal system (Leica Camera AG, Leitz Park, Wetzlar, Germany). The excitation wavelength for SYTO 9 and Calcofluor White MR2 were 488 and $405 \mathrm{~nm}$, and the emission wavelengths were 505 to 545 and 420 to $470 \mathrm{~nm}$, respectively.

\section{Bacterial growth assays.}

B. cereus $\mathrm{C} 1 \mathrm{~L}$ or mutant $\mathrm{M} 71$ cells were inoculated in $\mathrm{LB}$ broth and were cultured for $8 \mathrm{~h}$, were collected by centrifugation at $1500 \times g$ for $10 \mathrm{~min}$, and were resuspended in LB broth or M9CA broth (minimal M9CA broth with $0.1 \% \mathrm{NH}_{4} \mathrm{Cl}$ and $0.2 \%$ casamino acid) containing glucose of 0.1 or $0.5 \%$ or $0.5 \%$ fructose or maltose to a final optical density at $600 \mathrm{~nm}\left(\mathrm{OD}_{600}\right)$ of 0.04 . Next, $150 \mu \mathrm{l}$ of bacterial suspension in each medium was transferred into the individual wells of a 96-well microtiter plate, was cultured at $28^{\circ} \mathrm{C}$ with horizontal shaking at $50 \mathrm{rpm}$, and was subjected to $\mathrm{OD}_{600}$ measurement, using a SpectraMax 340PC microplate reader spectrophotometer (Molecular Devices, San Jose, CA, U.S.A.) at different timepoints. Sugar-free LB broth and M9CA broth were used as control media. Seven repetitions were performed for each treatment.

\section{Preparation of maize root exudates.}

The seeds of maize cv. Honey Jean No. 3 were surfacesterilized with $75 \%$ ethanol for $2 \mathrm{~s}$ and $2 \%$ sodium hypochlorite for $15 \mathrm{~min}$. Next, the maize seeds were washed with sterile distilled water three times and were kept in a moist chamber at $28^{\circ} \mathrm{C}$ in the dark for germination. Five maize seedlings with main roots approximately $2 \mathrm{~cm}$ long were aseptically transferred to $50 \mathrm{ml}$ of sterile distilled water and hydroponically cultured under a day and night cycle of 16 and $8 \mathrm{~h}$, respectively, at $28^{\circ} \mathrm{C}$ for 1 week. The root exudate-containing water was filtered through a $0.45-\mu \mathrm{m}$ MCE membrane (Merck Millipore, Billerica, MA, U.S.A.) and was then was lyophilized. The lyophilized powders from $50 \mathrm{ml}$ of root exudate-containing water were dissolved in $2.5 \mathrm{ml}$ of sterile distilled water, which was considered as $20 \times$ maize root exudate.

\section{Construction of the ptsGHI promoter-driven GFP reporter.}

The 554-bp DNA fragment of the ptsGHI promoter with the 5'terminal EcoRI site and 3'-terminal BamHI site was amplified from $B$. cereus $\mathrm{C} 1 \mathrm{~L}$ genomic DNA, using the primer pair for the ptsGHI promoter listed in Table 1, and was then cloned into plasmid pAD123 (Dunn and Handelsman 1999) (BCRC 41796) via $E c o$ RI and BamHI restriction enzyme sites, to generate a ptsGHI promoter-driven GFP reporter named pAD123-PptsG. The pAD123-Ppts $G$ and pAD123 vectors were separately transformed into E. coli GM2163 and then into B. cereus $\mathrm{C} 1 \mathrm{~L}$ in sequence by electroporation (Turgeon et al. 2006). GFP signals from $B$. cereus $\mathrm{C} 1 \mathrm{~L}$ transformants were examined by Leica DMR fluorescence microscopy equipped with a 41017 filter set (Chroma Technology Corp., Bellows Falls, VT, U.S.A.) (excitation filter of 450 to $490 \mathrm{~nm}$, dichroic mirror of $495 \mathrm{~nm}$, and emission filter of 500 to $550 \mathrm{~nm}$ ).

\section{Inducibility analysis of the ptsGHI promoter.}

The $B$. cereus $\mathrm{C} 1 \mathrm{~L}$ strains harboring the $\mathrm{pAD} 123-\mathrm{Ppts} G$ reporter or control vector pAD123 were used to assay the inducibility of the ptsGHI promoter in response to maize root exudate or its individual constituents. B. cereus $\mathrm{C} 1 \mathrm{~L}$ cells were inoculated and were cultured, in LB broth containing $10 \mu \mathrm{g}$ of chloramphenicol per milliliter, for $6 \mathrm{~h}$, were collected by centrifugation at $3,500 \times g$ for $1 \mathrm{~min}$, were resuspended in $\mathrm{AB}$ minimal medium $\left[0.6 \% \mathrm{Na}_{2} \mathrm{PO}_{4}, 0.3 \% \mathrm{KPO}_{3}, 0.3 \% \mathrm{NaCl}, 2 \%\right.$ $\left(\mathrm{NH}_{4}\right)_{2} \mathrm{SO}_{4}, 100 \mu \mathrm{M} \mathrm{CaCl} 2,3 \mu \mathrm{M} \mathrm{FeCl}, 1 \mathrm{mM} \mathrm{MgCl} \mathrm{Ml}_{2}$, and were cultured for a further 12 to $16 \mathrm{~h}$. Next, the bacterial cells were treated with $20 \times$ maize root exudate or each of its constituents of carbohydrates, sugar acids, and amino acids (Fan et al. 2012), at concentrations of $1,0.05$ and $0.05 \%$, respectively, for $16 \mathrm{~h}$ with shaking at $175 \mathrm{rpm}$. The $\mathrm{OD}_{600}$ value and fluorescence intensity (excitation at $485 \mathrm{~nm}$ and emission at $535 \mathrm{~nm}$ ) were measured using a SpectraMax 340PC microplate reader spectrophotometer (Molecular Devices) and Plate CHAMELEON V multitechnology plate reader (HIDEX, Turku, Finland), respectively. The promoter expression level per $\mathrm{OD}_{600}$ unit of bacterial cells in response to the treatments was represented as $\mathrm{AU} / \mathrm{OD}_{600}=($ fluorescence intensity of treatment fluorescence intensity of sterile deionized water control) / $\left(\mathrm{OD}_{600}\right.$ value of treatment $-\mathrm{OD}_{600}$ value of sterile deionized water control). Six repeats were performed for each treatment.

\section{Chemotaxis assay.}

The chemotaxis assay refers to the method reported by Mazumder et al. (1999), in which a sterile hypodermic needle ( $26 \mathrm{G} \times 1 / 2$ ") (Terumo Medical Corp., Tokyo) containing $100 \mu \mathrm{l}$ of test solution was plugged into a $200-\mu 1$ pipette tip filled with $200 \mu \mathrm{l}$ of a bacterial suspension of $5 \times 10^{7}$ or $1 \times 10^{8} \mathrm{CFU} / \mathrm{ml}$ and was placed horizontally for $45 \mathrm{~min}$. Next, the bacteria moving into the needle were counted by dilution plating. Test solutions included $20 \times$ maize root exudate, $1 \%$ glucose, maltose, isomaltose, mannose or trehalose, and 12.86 and $128.6 \mu \mathrm{M}$ glucose (equivalent to the glucose concentrations in $0.2 \times$ and $2 \times$ maize root exudate, respectively). The chemotaxis level toward the treatment, i.e., bacterial counts in the needle containing test solution/bacterial counts in the needle containing sterile water control, was represented as the RCR. An RCR value $>2$ was considered to be positive chemotaxis toward the treatment. Three repeats were performed for each treatment of individual bacterial strains.

\section{Glucose consumption measurement.}

Glucose consumption by $B$. cereus strains was examined following the method described by Houot and Watnick (2008). A 50- $\mu$ l overnight culture of B. cereus $\mathrm{C} 1 \mathrm{~L}$ or mutant $\mathrm{M} 71$ in $\mathrm{LB}$ broth was inoculated into $50 \mathrm{ml}$ of M9CA broth with $0.5 \%$ glucose and was cultured for 12 to $16 \mathrm{~h}$. Next, the bacterial cells were collected by centrifugation at $1,500 \times g$ for $10 \mathrm{~min}$, were resuspended in $50 \mathrm{ml}$ of $\mathrm{M} 9$ broth and were cultured for $1 \mathrm{~h}$, were washed twice with M9 broth, and were resuspended in M9 broth, to a final $\mathrm{OD}_{600}$ of 3.0. The bacterial suspension was mixed with an aliquot of $2 \%$ glucose solution in M9 broth, and the supernatant was recovered 30,60 , and $90 \mathrm{~s}$ later, separately, by centrifugation at $12,000 \times g$ for $30 \mathrm{~s}$ The glucose retained in the supernatant was measured using the glucose (HK) assay kit (Sigma-Aldrich Co.). Three repeats were performed for each bacterial strain.

\section{Swimming motility assay.}

The 12-h cultures of B. cereus CL1 and mutant M71 in LB broth were individually resuspended in sterile distilled water to 
a final $\mathrm{OD}_{600}$ of 0.8 . One 8-mm filter paper disk was placed in the center of soft LB or M9CA media $(0.3 \%$ agar) in a $9-\mathrm{cm}$ Petri dish and, then, was dipped with $30 \mu \mathrm{l}$ of $0.25,0.5,1.0,2.0$, or $4.0 \%$ glucose solution or sterile distilled water. Onemicroliter bacterial suspensions of $B$. cereus $\mathrm{C} 1 \mathrm{~L}$ and mutant M71 were oppositely inoculated on soft LB or M9CA medium $2 \mathrm{~cm}$ away from the filter paper disk. The plates of LB and M9CA media were incubated at $28^{\circ} \mathrm{C}$ for 24 to $50 \mathrm{~h}$, and the colony size and morphology were compared. Four plates were used for each treatment in a single assay, and three repeated assays were performed.

\section{Quantification of biofilm formation.}

A microtiter plate-based crystal violet staining assay was used to quantify the biofilm formation of B. cereus strains. The 12-h cultures of $B$. cereus $\mathrm{C} 1 \mathrm{~L}$ and mutant M71 in LB broth were individually resuspended in sterile distilled water to a final $\mathrm{OD}_{600}$ of 0.1 or 0.08 . A $75-\mu$ l bacterial suspension of $\mathrm{OD}_{600}=0.1$ or 0.8 was mixed with $75 \mu \mathrm{l}$ of $2 \times \mathrm{LB}$ or $2 \times \mathrm{M} 9 \mathrm{CA}$ broth containing $0,0.2$, or $1.0 \%$ glucose in the wells of a 96 well microtiter plate. After incubation at $28^{\circ} \mathrm{C}$ with 50 -rpm shaking for $34 \mathrm{~h}$, the culture mixture was subjected to measurement of $\mathrm{OD}_{600}$, using the SpectraMax 340PC microplate reader spectrophotometer (Molecular Devices), and was then removed. The wells were gently washed with sterile distilled water, were incubated with $180 \mu \mathrm{l}$ of $0.1 \%$ (vol/vol) crystal violet (Sigma-Aldrich Co.) for $30 \mathrm{~min}$, were rinsed with sterile distilled water for $10 \mathrm{~min}$, three times, and were air-dried. The biofilm-trapped crystal violet in the well was dissolved with $200 \mu \mathrm{l}$ of $30 \%$ acetic acid and were subjected to measurement of $\mathrm{OD}_{595}$, using the SpectraMax 340PC microplate reader spectrophotometer (Molecular Devices) 30 min later. Seven repeats were used in each treatment of individual bacterial strains in a single assay, and two repeated assays were performed.

\section{GC-MS analysis.}

B. cereus CL1 or mutant M71 was inoculated in LB broth with or without $1 \%$ glucose and were cultured for 12 to $16 \mathrm{~h}$. The culture supernatants were diluted to a final $\mathrm{OD}_{600}$ of 2 with LB broth, were recovered by centrifugation at $12,000 \times g$ at $4^{\circ} \mathrm{C}$ for $10 \mathrm{~min}$, were filtered through a $0.45-\mu \mathrm{m}$ polyvinylidene diflouride membrane (Merck Millipore), were mixed with isoamyl alcohol to a final concentration of $100 \mathrm{ppm}$ as the internal standard, and were saturated with sodium chloride to increase density. Next, the supernatants were extracted with an equal volume of ethyl acetate, and the upper nonaqueous phase was collected and concentrated in a GC-MS vial. GC-MS analysis was performed using $6890 \mathrm{GC}$ equipped with a $30-\mathrm{m}$ HP-5MS capillary column $(0.25-\mathrm{mm}$ internal diameter and $25-\mu \mathrm{m}$ film thickness) and a 5975C mass selective detector (all from Agilent Technologies Inc., Santa Clara, CA, U.S.A.). a $1-\mu \mathrm{l}$ sample was loaded onto the injector at $230^{\circ} \mathrm{C}$ in a split mode with a split ratio of 9:1, and the flow speed of the carrier gas helium was $1 \mathrm{ml} / \mathrm{min}$. The column oven temperature was initially maintained at $40^{\circ} \mathrm{C}$ for $5 \mathrm{~min}$, ramped to $130^{\circ} \mathrm{C}$ with a rate of $10^{\circ} \mathrm{C}$ per minute, and was maintained for 1 min and, then, ramped to $230^{\circ} \mathrm{C}$ with a rate of $20^{\circ} \mathrm{C}$ per minute. Mass spectra were scanned in a range of 20 to 400 atomic mass units, and the compounds in the bacterial extract were identified by comparing their mass spectra with those in standard reference databases (National Institute of Standards and Technology, Gaithersburg, MD, U.S.A.). To quantify the relative amounts of acetoin and 2,3-butanediol produced by B. cereus $\mathrm{C} 1 \mathrm{~L}$ and mutant M71, acetoin or 2,3-butanediol standard solutions of $20,40,60,80$, and $100 \mathrm{ppm}$, which also contained $100 \mathrm{ppm}$ of isoamyl alcohol as an internal standard, were assayed by
GC-MS following the above description. The ion chromatogram and signal intensity of acetoin and 2,3-butanediol standard solutions were integrated using 5975C data analysis software (Agilent Technologies Inc.) to generate a calibration curve to quantify acetoin or 2,3-butanediol in bacterial samples. Three repeats of the GS-MS assay for each treatment of individual bacterial strains were performed.

\section{Antagonistic assay of VOCs against the fungus.}

A 5- $\mu 1$ spore suspension of $C$. heterostrophus $\mathrm{CH} 1$ at $5 \times 10^{4}$ spores/ml was inoculated on PDA in one compartment of a divided Petri plate with a diameter of $9 \mathrm{~cm}$, and $20 \mu \mathrm{l} \mathrm{of}$ $100 \mathrm{mM}$ acetoin or 2,3-butanediol solution was dropped onto a filter paper disc of $0.25 \mathrm{~cm}^{2}$ in the other compartment of the same plate. Next, the plate was sealed with parafilm and was incubated at $28^{\circ} \mathrm{C}$. The diameter and morphology of the fungal colony were recorded at 5 to 10 days after incubation. Sterile deionized water was used to replace acetoin and 2,3-butanediol as a control. Three repeats were performed for each treatment.

\section{Detection of plant defense.}

Four-week-old maize plants were drenched with bacterial suspensions of $B$. cereus strains of $1 \times 10^{8} \mathrm{CFU} / \mathrm{ml}$ or acetoin or 2,3-butanediol solution of $1 \mathrm{mM}$ twice at 3-day intervals, and then, the leaves were detached and sprayed with a C. heterostrophus $\mathrm{CH} 1$ spore suspension of $5 \times 10^{4}$ spores $/ \mathrm{ml}$ 1 day later. The inoculated leaves were kept moist at $28^{\circ} \mathrm{C}$ until the histochemical staining assays of the plant defense. ROS accumulation in the leaves was detected by staining with $1 \mathrm{mg}$ of DAB per milliliter. Fungal growth or plant cell death and callose deposition were visualized by trypan blue staining ( $0.05 \%$ trypan blue in lactophenol) followed by aniline blue staining $\left(0.05 \%\right.$ aniline blue in $\left.150 \mathrm{mM} \mathrm{KH} \mathrm{KO}_{4}, \mathrm{pH} 9.5\right)$. $\mathrm{Next}$, fungal growth and plant cell death, stained by trypan blue, and callose deposition, stained by aniline blue, were observed under bright field and UV light, respectively, using a Leica DMIL florescent microscope equipped with a Leica A filter set (bandpass filter 340 to $380 \mathrm{~nm}$, dichroic mirror $400 \mathrm{~nm}$, longpass filter $425 \mathrm{~nm}$ ).

\section{Statistical analysis.}

Statistical analysis was performed using SAS 9.2 software (SAS Institute Inc., Cary, NC, U.S.A.). Levene's test was used to check the homogeneity of variance. One-way analysis of variance followed by Fisher's least significant difference test at a significant level of $5 \%$ was performed.

\section{ACKNOWLEDGMENTS}

We thank S. T. Liu for providing pD917 in the transposon-based insertional mutagenesis and T.-C. Lin for technical support.

\section{LITERATURE CITED}

Badri, D. V., and Vivanco, J. M. 2009. Regulation and function of root exudates. Plant Cell Environ. 32:666-681.

Burketova, L., Trda, L., Ott, P. G., and Valentova, O. 2015. Bio-based resistance inducers for sustainable plant protection against pathogens. Biotechnol. Adv. 33:994-1004.

Cabrera-Valladares, N., Martínez, L. M., Flores, N., Hernández-Chávez, G., Martínez, A., Bolívar, F., and Gosset, G. 2012. Physiologic consequences of glucose transport and phosphoenolpyruvate node modifications in Bacillus subtilis 168. J. Mol. Microbiol. Biotechnol. 22:177-197.

Chang, L.-K., Chen, C.-L., Chang, Y.-S., Tschen, J. S.-M., Chen, Y.-M., and Liu, S.-T. 1994. Construction of Tn917ac1, a transposon useful for mutagenesis and cloning of Bacillus subtilis genes. Gene 150:129-134.

Choudhary, D. K., and Johri, B. N. 2009. Interactions of Bacillus spp. and plants-With special reference to induced systemic resistance (ISR). Microbiol. Res. 164:493-513. 
Chung, J. H., Song, G. C., and Ryu, C. M. 2016. Sweet scents from good bacteria: Case studies on bacterial volatile compounds for plant growth and immunity. Plant Mol. Biol. 90:677-687.

Clore, G. M., and Venditti, V. 2013. Structure, dynamics and biophysics of the cytoplasmic protein-protein complexes of the bacterial phosphoenolpyruvate: Sugar phosphotransferase system. Trends Biochem. Sci. 38:515-530.

D’Alessandro, M., Erb, M., Ton, J., Brandenburg, A., Karlen, D., Zopfi, J., and Turlings, T. C. J. 2014. Volatiles produced by soil-borne endophytic bacteria increase plant pathogen resistance and affect tritrophic interactions. Plant Cell Environ. 37:813-826.

De Reuse, H., and Danchin, A. 1991. Positive regulation of the pts operon of Escherichia coli: Genetic evidence for a signal transduction mechanism. J. Bacteriol. 173:727-733.

De Reuse, H., Kolb, A., and Danchin, A. 1992. Positive regulation of the expression of the Escherichia coli pts operon: Identification of the regulatory regions. J. Mol. Biol. 226:623-635.

Deutscher, J., Francke, C., and Postma, P. W. 2006. How phosphotransferase system-related protein phosphorylation regulates carbohydrate metabolism in bacteria. Microbiol. Mol. Biol. Rev. 70:939-1031.

Dunn, A. K., and Handelsman, J. 1999. A vector for promoter trapping in Bacillus cereus. Gene 226:297-305.

Fan, B., Carvalhais, L. C., Becker, A., Fedoseyenko, D., von Wirén, N., and Borriss, R. 2012. Transcriptomic profiling of Bacillus amyloliquefaciens FZB42 in response to maize root exudates. BMC Microbiol. 12:116-128.

Fincheira, P., and Quiroz, A. 2018. Microbial volatiles as plant growth inducers. Microbiol. Res. 208:63-75.

Gao, T., Ding, M., Yang, C. H., Fan, H., Chai, Y., and Li, Y. 2019. The phosphotransferase system gene $p t s H$ plays an important role in MnSOD production, biofilm formation, swarming motility, and root colonization in Bacillus cereus 905. Res. Microbiol. 170:86-96.

Gao, T., Foulston, L., Chai, Y., Wang, Q., and Losick, R. 2015. Alternative modes of biofilm formation by plant-associated Bacillus cereus. MicrobiologyOpen 4:452-464.

Gao, T., Li, Y., Ding, M., Chai, Y., and Wang, Q. 2017. The phosphotransferase system gene ptsI in Bacillus cereus regulates expression of sodA2 and contributes to colonization of wheat roots. Res. Microbiol. 168:524-535.

Garrity, L. F., and Ordal, G. W. 1995. Chemotaxis in Bacillus subtilis: How bacteria monitor environmental signals. Pharmacol. Ther. 68:87-104.

Garrity, L. F., Schiel, S. L., Merrill, R., Reizer, J., Saier, M. H., Jr., and Ordal, G. W. 1998. Unique regulation of carbohydrate chemotaxis in Bacillus subtilis by the phosphoenolpyruvate-dependent phosphotransferase system and the methyl-accepting chemotaxis protein McpC. J. Bacteriol. 180:4475-4480.

Gouda, S., Kerry, R. G., Das, G., Paramithiotis, S., Shin, H. S., and Patra J. K. 2018. Revitalization of plant growth promoting rhizobacteria for sustainable development in agriculture. Microbiol. Res. 206:131-140.

Gowda, G. A. N., and Djukovic, D. 2014. Overview of mass spectrometrybased metabolomics: Opportunities and challenges. Methods Mol. Biol. 1198:3-12.

Gunina, A., and Kuzyakov, Y. 2015. Sugars in soil and sweets for microorganisms: Review of origin, content, composition and fate. Soil Biol. Biochem. 90:87-100.

Houot, L., and Watnick, P. I. 2008. A novel role for enzyme I of the Vibrio cholerae phosphoenolpyruvate phosphotransferase system in regulation of growth in a biofilm. J. Bacteriol. 190:311-320.

Huang, C. J., Liu, Y. H., Yang, K. H., and Chen, C. Y. 2012a. Physiological response of Bacillus cereus $\mathrm{C} 1 \mathrm{~L}-$-induced systemic resistance in lily against Botrytis leaf blight. Eur. J. Plant Pathol. 134:1-12.

Huang, C. J., Tsay, J. F., Chang, S. Y., Yang, H. P., Wu, W. S., and Chen, C. Y. 2012b. Dimethyl disulfide is an induced systemic resistance elicitor produced by Bacillus cereus C1L. Pest Manag. Sci. 68:1306-1310.

Huang, C. J., Yang, K. H., Liu, Y. H., Lin, Y. J., and Chen, C. Y. 2010. Suppression of southern corn leaf blight by a plant growth-promoting rhizobacterium Bacillus cereus C1L. Ann. Appl. Biol. 157:45-53.

Huang, C. J., Zheng, P. X., Ou, J. Y., Lin, Y. C., and Chen, C. Y. 2017. Complete genome sequence of Bacillus cereus $\mathrm{C} 1 \mathrm{~L}$, a plant growthpromoting rhizobacterium from the rhizosphere of Formosa lily in Taiwan. Genome Announc. 5:e01290-17.

Hütsch, B. W., Augustin, J., and Merbach, W. 2002. Plant rhizodepositionan important source for carbon turnover in soils. J. Plant Nutr. Soil Sci. 165:397-407.

Jahreis, K., Pimentel-Schmitt, E. F., Brückner, R., and Titgemeyer, F. 2008 Ins and outs of glucose transport systems in eubacteria. FEMS Microbiol. Rev. 32:891-907.

Ji, X. J., Huang, H., and Ouyang, P. K. 2011. Microbial 2,3-butanediol production: A state-of-the-art review. Biotechnol. Adv. 29:351-364.
Joyet, P., Bouraoui, H., Aké, F. M. D., Derkaoui, M., Zébré, A. C., Cao, T. N., Ventroux, M., Nessler, S., Noirot-Gros, M. F., Deutscher, J., and Milohanic, E. 2013. Transcription regulators controlled by interaction with enzyme IIB components of the phosphoenolpyruvate: Sugar phosphotransferase system. Biochim. Biophys. Acta 1834:1415-1424.

Kanchiswamy, C. N., Malnoy, M., and Maffei, M. E. 2015. Chemical diversity of microbial volatiles and their potential for plant growth and productivity. Front. Plant Sci. 6:151.

Koek, M. M., Jellema, R. H., van der Greef, J., Tas, A. C., and Hankemeier, T. 2011. Quantitative metabolomics based on gas chromatography mass spectrometry: Status and perspectives. Metabolomics 7:307-328.

Koek, M. M., Muilwijk, B., van der Werf, M. J., and Hankemeier, T. 2006. Microbial metabolomics with gas chromatography/mass spectrometry. Anal. Chem. 78:1272-1281.

Kotrba, P., Inui, M., and Yukawa, H. 2001. Bacterial phosphotransferase system (PTS) in carbohydrate uptake and control of carbon metabolism. J. Biosci. Bioeng. 92:502-517.

Kristich, C. J., Glekas, G. D., and Ordal, G. W. 2003. The conserved cytoplasmic module of the transmembrane chemoreceptor McpC mediates carbohydrate chemotaxis in Bacillus subtilis. Mol. Microbiol. 47:1353-1366.

Lai, Y. R., Lin, P. Y., Chen, C. Y., and Huang, C. J. 2016. Feasible management of southern corn leaf blight via induction of systemic resistance by Bacillus cereus $\mathrm{C} 1 \mathrm{~L}$ in combination with reduced use of dithiocarbamate fungicides. Plant Pathol. J. 32:481-488.

Lemon, K. P., Earl, A. M., Vlamakis, H. C., Aguilar, C., and Kolter, R. 2008. Biofilm development with an emphasis on Bacillus subtilis. Curr Top. Microbiol. Immunol. 322:1-16.

Lister, J. L., and Horswill, A. R. 2014. Staphylococcus aureus biofilms: Recent developments in biofilm dispersal. Front. Cell. Infect. Microbiol. 4:178.

Liu, Y. H., Huang, C. J., and Chen, C. Y. 2008. Evidence of induced systemic resistance against Botrytis elliptica in lily. Phytopathology 98: 830-836.

Lu, H., Sun, J., and Zhu, L. 2017. The role of artificial root exudate components in facilitating the degradation of pyrene in soil. Sci. Rep. 7: 7130

Marinus, M. G., Carraway, M., Frey, A. Z., Brown, L., and Arraj, J. A. 1983. Insertion mutations in the dam gene of Escherichia coli K-12. Mol. Gen. Genet. 192:288-289.

Mazumder, R., Phelps, T. J., Krieg, N. R., and Benoit, R. E. 1999. Determining chemotactic responses by two subsurface microaerophiles using a simplified capillary assay method. J. Microbiol. Methods 37: 255-263.

Meziane, H., Van der Sluis, I., van Loon, L. C., Höfte, M., and Bakker, P. A. H. M. 2005. Determinants of Pseudomonas putida WCS358 involved in inducing systemic resistance in plants. Mol. Plant Pathol. 6: 177-185.

Mhlongo, M. I., Piater, L. A., Madala, N. E., Labuschagne, N., and Dubery, I. A. 2018. The chemistry of plant-microbe interactions in the rhizosphere and the potential for metabolomics to reveal signaling related to defense priming and induced systemic resistance. Front. Plant Sci. 9:112.

Neumann, S., Grosse, K., and Sourjik, V. 2012. Chemotactic signaling via carbohydrate phosphotransferase systems in Escherichia coli. Proc. Natl. Acad. Sci. U.S.A. 109:12159-12164.

Paulsen, I. T., Chauvaux, S., Choi, P., and Saier, M. H., Jr. 1998 Characterization of glucose-specific catabolite repression-resistant mutants of Bacillus subtilis: Identification of a novel hexose: $\mathrm{H}^{+}$ symporter. J. Bacteriol. 180:498-504.

Roncato-Maccari, L. D. B., Ramos, H. J. O., Pedrosa, F. O., Alquini, Y., Chubatsu, L. S., Yates, M. G., Rigo, L. U., Steffens, M. B. R., and Souza, E. M. 2003. Endophytic Herbaspirillum seropedicae expresses nif genes in gramineous plants. FEMS Microbiol. Ecol. 45:39-47.

Rudrappa, T., Czymmek, K. J., Paré, P. W., and Bais, H. P. 2008. Rootsecreted malic acid recruits beneficial soil bacteria. Plant Physiol. 148: 1547-1556.

Schmalisch, M. H., Bachem, S., and Stülke, J. 2003. Control of the Bacillus subtilis antiterminator protein GlcT by phosphorylation. Elucidation of the phosphorylation chain leading to inactivation of GlcT. J. Biol. Chem. 278:51108-51115.

Sharifi, R., and Ryu, C. M. 2018. Revisiting bacterial volatile-mediated plant growth promotion: Lessons from the past and objectives for the future. Ann. Bot. 122:349-358.

Stülke, J., Martin-Verstraete, I., Zagorec, M., Rose, M., Klier, A., and Rapoport, G. 1997. Induction of the Bacillus subtilis ptsGHI operon by glucose is controlled by a novel antiterminator, GlcT. Mol. Microbiol. 25:65-78. 
Tojo, S., Kumamoto, K., Hirooka, K., and Fujita, Y. 2010. Heavy involvement of stringent transcription control depending on the adenine or guanine species of the transcription initiation site in glucose and pyruvate metabolism in Bacillus subtilis. J. Bacteriol. 192:1573-1585.

Turgeon, N., Laflamme, C., Ho, J., and Duchaine, C. 2006. Elaboration of an electroporation protocol for Bacillus cereus ATCC 14579. J. Microbiol. Methods 67:543-548.

Wang, M., Ford, R. M., and Harvey, R. W. 2008. Coupled effect of chemotaxis and growth on microbial distributions in organic-amended aquifer sediments: Observations from laboratory and field studies. Environ. Sci. Technol. 42:3556-3562.

Whipps, J. M. 1990. Carbon economy. Pages 59-97 in: The Rhizosphere. J. M. Lynch, ed. John Wiley \& Sons Ltd, Essex, U.K.

Xu, Y., Jiang, Y., Li, X., Sun, B., Teng, C., Yang, R., Xiong, K., Fan, G., and Wang, W. 2018. Systematic characterization of the metabolism of acetoin and its derivative ligustrazine in Bacillus subtilis under microoxygen conditions. J. Agric. Food Chem. 66:3179-3187.

Xu, Y. B., Chen, M., Zhang, Y., Wang, M., Wang, Y., Huang, Q. B., Wang, X., and Wang, G. 2014. The phosphotransferase system gene ptsI in the endophytic bacterium Bacillus cereus is required for biofilm formation, colonization, and biocontrol against wheat sharp eyespot. FEMS Microbiol. Lett. 354:142-152.

Zhang, C., Zhang, R., and Yuan, J. 2017. Growth-dependent behavioral difference in bacterial chemotaxis. Phys. Rev. E 95:062404.

Zhang, N., Yang, D., Wang, D., Miao, Y., Shao, J., Zhou, X., Xu, Z., Li, Q., Feng, H., Li, S., Shen, Q., and Zhang, R. 2015. Whole transcriptomic analysis of the plant-beneficial rhizobacterium Bacillus amyloliquefaciens SQR9 during enhanced biofilm formation regulated by maize root exudates. BMC Genomics 16: 685. 